\title{
A review of fire blocking technologies for soft furnishings
}

\author{
Shonali Nazaré* and Rick D Davis
}

\begin{abstract}
Fire barrier fabrics are expected to play an increasingly important role in complying with existing and proposed soft furnishing flammability regulations in the US. The number of commercial fire blocking technologies is large in order to accommodate the vast requirements of the consumers, manufacturers, and regulatory agencies. Generally, highloft, nonwoven fiber battings are used in residential mattress applications, whereas coated or laminated textiles are more common in institutional and upholstered furnishing applications. Successfully achieving the desired level of fire protection requires appropriate matching of the barrier fabric to the desired characteristics of the soft furnishing. Barrier material selection for soft furnishings is generally a process of trial and error due to significant measurement science gaps.

In 2009, the National Institute of Science and Technology and American Fiber Manufacturers Association held a workshop on fire blocking barrier fabrics for soft furnishings to discuss the past, present, and future state of the barrier materials in the US. This manuscript is based on knowledge obtained from the workshop and the subsequent knowledge gathered from literature and stakeholders. Several fire blocking technologies have been explored to reduce the flammability of soft furnishings by preventing or delaying direct flame impingement and heat transfer from the flames or molten polymer to the core components. While previous studies reported on use of fire barriers to comply with full-scale testing of soft furnishing items, they failed to report on assessment of barrier materials as isolated components. In addition to a few examples that demonstrate the complexity that makes a priori selection of fire barrier materials difficult, various fire blocking technologies are discussed in this report with respect to material type, fiber content, and fire blocking mechanisms. Potential test methods for characterizing barrier performance are reviewed. Future trends in fire blocking materials are also briefly described.
\end{abstract}

Keywords: Soft furnishings, Upholstered furniture, Barrier fabrics, Mattress, Flammability, Review, Regulations

\section{Introduction}

Fires in which a soft furnishing product is the first item ignited accounts for $5 \%$ of all U.S. residential fires annually, but are responsible for a disproportionately high fraction of fire losses (Hall 2008; Hall \& Harwood 1989; Greene \& Miller 2006; Ahrens 2008; Horrocks 2001; Bwalya et al. 2009). The goal of a number of current and proposed flammability regulations is to reduce these fire losses. Existing flammability regulations for soft furnishings mainly address upholstered chairs and mattresses. The approaches manufacturers have taken to comply with these regulations are fairly consistent. To comply with the California Bureau of Home Furnishings and

\footnotetext{
* Correspondence: shonalisg@yahoo.com

National Institute of Standards and Technology, Engineering Laboratory, 100 Bureau Drive, Gaithersburg, MD 20899-8665, USA
}

Thermal Insulation (BHFTI) soft furnishings flammability regulations (e.g., Cal TB 129 (Technical Bulletin 129 1992) and Cal TB 603 (California TB 603 et al. 1633) for mattresses and Cal TB 133 (Technical Bulletin 133 1991) for upholstered chairs), manufacturers use a combination of flame retardant (FR) foam, FR cover fabrics, and/or barrier fabrics. In the UK however, the requirements of furniture flammability regulation for domestic furnishings (Consumer Protection Act 1987) were mainly addressed by using flame retardant back-coated cover fabric in combination with filling materials, including PUF, which are required to pass stringent ignition criteria (Chivas et al. 2009). Currently, there is no federal flammability regulation for residential upholstered furniture in the U.S., but Consumer Products Safety Commission (CPSC) has now proposed a regulation (CPSC 16

\section{穴}


CFR Part 1634 (16 CFR Part 1634)) that defines a smoldering and open flame metric for these products. To comply with the 1,634 open flame ignition test, it is anticipated that barrier materials will be employed in residential upholstered furniture. To comply with the recent CPSC's mattress flammability (open-flame) regulation 16 CFR Part 1633(16 CFR 1633), the manufacturers are solely relying on barrier materials. In addition, restrictions on flame retardants are increasing due to sustainability regulations (Chivas et al. 2009; European et al. 1907). Thus, fire barrier materials are expected to play an increasingly important role in reducing the fire hazard of soft furnishings. Other regulatory approaches include reducing risk of ignition through reduced ignition propensity cigarettes, reducing fire spread through residential sprinklers, and reducing the inherent fire hazard of fuel sources through lower heat release (HR) mattresses.

Several fire blocking technologies have been explored to reduce the flammability of soft furnishings by preventing or delaying direct flame impingement and heat transfer from the flames or molten polymer to the core components. While previous studies (Fesman \& Jacobs 1989; Damant \& Nurbakhsh 1992; Eggestad \& Johnsen 1987; Gallagher 1993; Damant 1996; Ohlemiller \& Shields 1995) reported on use of fire barriers to comply with full-scale testing of soft furnishing items, they failed to report on assessment of barrier materials as isolated components. Very little is known about fire performance requirements of these barrier materials that are critical to complying with full-scale fire regulations for mattresses and upholstered furniture. Selection of barrier materials therefore becomes a process of trial and error due to significant measurement science gaps. Current test methods for barrier materials are based on pass/fail criteria and do not quantify barrier effectiveness. Furthermore, successfully achieving the desired level of fire protection requires appropriate matching of the barrier fabric to the desired characteristics of the soft furnishing. In addition to a few examples that demonstrate the complexity that makes a priori selection of fire barrier materials difficult, various fire blocking technologies are discussed in this report with respect to material type, fiber content, and fire blocking mechanisms. Potential test methods for characterizing barrier performance are reviewed.

For more than 30 years, the Fire Research Division at the National Institute of Standards and Technology (NIST) has conducted research that has significantly contributed to the current understanding of soft furnishing flammability and the development of current standardized testing tools and methods (Ohlemiller \& Gann 2002; Ohlemiller \& Shields 2008; Ohlemiller 2008). In 2009 , in order to facilitate the development of costeffective fire barrier materials, NIST began conducting research focused on developing validated tools that accurately measure barrier performance, enabling the understanding of the association of material attributes with fire blocking performance, and evaluating new fire blocking technologies. To start this new research focus, NIST and the American Fiber Manufacturers Association (AMFA) sponsored a Barrier Fabric Workshop with participants from manufacturing, government, and academic institutes. This review manuscript summarizes the landscape of barrier materials based on the knowledge gained from the workshop, extensive literature review, stakeholder collaborations, and research activities at NIST.

\section{Factors affecting flammability of soft furnishings}

A large selection of soft furnishings can be found in the marketplace, stemming from the wide variety of customer needs for functionality, aesthetics, and affordability. To meet these needs, manufacturers use a range of textile materials, including woven fabrics, knitted fabrics, and non-woven highloft battings. Upholstered products are available in a wide range of geometries, frame and support materials, and physical construction types. It is not well understood to what extent any of these variations impact the fire hazard of soft furnishings. NIST is currently conducting research to address these knowledge gaps (Reduced risk of furniture fire hazard 2999).

Even though the function, construction, geometry, and materials used in soft furnishings differ, there are a few general similarities with respect to their flammability. For example, all soft furnishing products have a supporting frame, cushioning layers, and an outer covering fabric; each of which is generally flammable to some extent. Fiber chemistry has a strong influence on the flammability behavior of a given component. For example, upon exposure to an ignition source, the outer covering fabric could ignite, char, or melt. The formation of a smoldering char may cause localized heating of the underlying components, resulting in thermal degradation of the foam and the release of volatile gases. These volatiles can ignite and support sustained flaming until all the combustible materials have been consumed. Flammability processes can be improved by preventing or delaying the ignition process using a technology that prevents thermal penetration (e.g., fire barrier material) or more thermally stable cushioning material. A melting covering fabric is another potential alternative to prevent ignition if the melting fabric selfextinguishes as it shrinks away from the ignition source. This requires a low heat release with no other easily ignitable materials on the surface. This route can be desirable to manufacturers since many lower cost fabrics have this 'melt-shrinking' characteristic. Since this type of covering fabric provides resistance against smoldering ignition but not against open flame, other fire retarding technology will be necessary (e.g., barrier materials and/or FR foam). 
The fabric design and construction can also impact the flammability of soft furnishings. For jacquard woven fabrics, the design can affect the peak heat release rate (PHRR) even if the basic yarn composition within the fabric remains unchanged. For example, design patterns with large motifs may have different burning characteristics than those with small motifs (Horrocks et al. 2001). This is extremely important as the PHRR is often a critical performance metric for soft furnishing standards/regulations. One of the approaches to prevent heat transfer through the fabric (to the highly flammable foam core) is to use "pile" fabric structure that have raised fibers on the base fabric. Ignition of pile fibers creates what is called "surface flashing", which is a very rapid spread of flames across the surface of the soft furnishing due to the easy ignitability and rapid consumption of these fibers. With low heat generating fibers, the flame spreads rapidly and consumes the raised fibers without igniting the base fabric. Pile or velvet fabrics are examples of such materials commonly used in residential upholstered furniture.

Although a flexible polyurethane foam (PUF) core is common in both mattresses and upholstered furniture; other filling materials are also quite popular (e.g., cotton battings, polyester fiber battings, expanded polystyrene beads, feathers, and downs (fine feathers)) (Paul et al. 2004). Compliance with flammability regulations is often achieved by preventing PUF from being exposed to heat and/or flame, as the fire hazard can significantly increase once PUF is ignited (Ohlemiller \& Shields 2008). The flammability and flame retardancy of PUF has been well studied and widely reported (Krämer et al. 2010; Chattopadhyay \& Webster 2009; Lefebvre et al. 2004; Levchik \& Weil 2004). However, there is still a lack of fundamental understanding of the relation between PUF attributes (e.g., surface area, air permeability, etc.), the manufacturing process (e.g., catalyst type and concentration), and PUF flammability (in both smoldering and open-flame performance). Knowledge gaps also include the flammability of other fill materials used in modern furniture. Loose-fill materials such as shredded PUF, "slickened" polyester fiber, and expanded polyurethane beads could be even more flammable than the typical PUF. These knowledge gaps are currently being addressed at NIST (Gann et al. 2011).

Mattresses and upholstered furniture represent distinctly different fire threats due to variations in their construction geometries and usage. In developed countries, where fire incidences are systematically recorded, the residential fire fatality statistics are dominated by these two product categories of soft furnishings, which are separately discussed below.

\section{Mattresses}

A mattress set essentially consists of three main components: a frame, foundation and mattress. Mattresses are classified by the support system, which can be an innerspring, solid PUF, cotton batting, air or water. A typical innerspring mattress, which accounts for nearly $80 \%$ of the U.S. market, is covered by a comfort layer on one side for single-sided mattresses or on both sides for double-sided mattresses. The comfort layer is divided into three sub categories: cushioning layer, insulator and quilt. The quilt is the top layer of the mattress and is constructed of the ticking (the outer cover fabric of a mattress) and a low density PUF or fiber batting laminated or stitched to the underside of the ticking. The insulator and the cushioning layers may be stacked in varying sequences between the quilt and the innerspring support. The insulating layer is often a light-weight, low density nonwoven batting (or layers of nonwoven fabrics), whereas the cushioning layer may include flat or convoluted PUF, shredded pads of compressed polyester, or fiber battings.

\section{Contributions to flammability}

The flammability of a mattress depends on each of the components described above, along with the possible synergism or antagonism that may exist among component materials (Nurbakhsh \& Mc Cormack 1998). This section briefly describes some of the factors that have impact on mattress flammability and the severity of bedroom fires in general. A more detailed review of mattress construction and materials as they relate to flammability regulations and testing is under preparation (Nazare \& Davis 2011).

\section{Contributions to flammability: construction}

Mattress flammability is significantly impacted by its construction. The fuel load of a solid PUF core mattress is significantly greater than that of an innerspring mattress with similar filling material. Intuitively, the fuel load would be expected to be an important factor in determining the fire performance of the mattress set. However, this assumption may only be partially accurate, since an innerspring mattress filled with melamine-type foam has been shown to result in higher heat release rates than a solid core mattress of the same size filled with similar melamine-type foam (Damant \& Nurbakhsh 1992). This may be attributed to the reduced air flow within the more closed structure of the solid core mattress, which limits heat release and fire growth, whereas the open structure of the innerspring allows air to flow freely. In the latter case, pyrolysis is limited only by the types of materials used in mattress construction.

\section{Contributions to flammability: tickings}

The most common tickings used in current mattresses are pile fabrics, knits, and jacquard woven fabrics. With an increased focus on allergies, physiological comfort, 
and fire safety, a variety of functional coatings (e.g., water-proof, anti-bacterial, anti-fungal, and/or FR finishes) are now applied to mattress tickings. The majority of modern ticking materials have a high polypropylene and/or polyester fiber count, with the fiber content varying significantly with the fabric structure and design pattern. These tickings are highly flammable, but are not necessarily a greater fire threat, as these synthetic fabrics tend to melt away from the ignition source and selfextinguish. Cotton tickings are often considered "sacrificial", as they pyrolyze quickly and generate low heat, thereby resulting in little heat transfer to the inner layers of the mattress. While cotton, polyester and polypropylene fibers dominate the ticking industry, blends of luxury fibers (e.g., wool and silk) are becoming more prevalent. Wool and silk are inherently low flammability fibers. Fibers made from renewable resources (e.g., corn, soybean and bamboo) are also gaining popularity as more environmentally friendly alternatives. Viscose rayon derived from bamboo is of particularly high interest because of its inherent anti-bacterial and anti-fungal properties and its good breathability and moisture absorption (Ticking 2005). However, very little is known about the flammability of these 'green' alternatives.

Quilting patterns are very common in mattresses. While quilting imparts more cushioning and insulation by creating large air pockets within the quilted structure, the quilting pattern itself also impacts the burning behavior. When tested under the cone calorimeter, composite specimens with quilted tickings exhibit slightly higher total heat release rates (THR) values as compared to non-quilted ticking specimens (Fritz \& Hunsberger 1997). One of the probable reasons for this kind of fire performance is that flame spread in quilted specimens is slower. The quilted material therefore burns slowly but completely to give higher THR values.

\section{Contributions to flammability: interaction with nearby items} The mattress is only one of many contributing products dictating the magnitude of a bedroom fire. A bedroom frequently contains a bed covered with bedclothes (e.g., blankets, sheets, dust covers, and pillows), carpet, draperies, other furniture, and items that may be found both on and adjacent to the bed (e.g., toys, stuffed animals, and clothes). The purpose of requiring a conservative heat release metric for mattresses is to reduce the probability of a mattress-initiated fire spreading to other components in the room or a fire on one of the other items in the room igniting the mattress. Ultimately, the degree with which a mattress becomes involved and the severity of the fire will depend not only on the flammability of the mattress, but also on the flammability of other items on and near the bed, which may or may not have to meet flammability requirements. For example, a recent study showed that the bedclothes, including sheets, comforter and blanket, on a queen size or larger mattress set are sufficient to take a standard room to flashover ( $>1,000 \mathrm{~kW} \mathrm{HRR)} \mathrm{(Ohlemiller} \mathrm{\&} \mathrm{Gann} \mathrm{2003).}$ To date, there are no US federal flammability regulations for bedclothes.

\section{Upholstered furniture}

Upholstered furniture is available in various styles, sizes, geometries, constructions, and materials intended to provide the consumer with the appropriate balance of function, aesthetics, comfort, durability, and cost. Predicting flammability of upholstered furniture is extremely difficult because of insufficient knowledge on how these variations in materials and design interact synergistically or antagonistically to influence flammability. Our current understanding of the relationship of upholstered furniture design parameters to flammability is primarily based on an extensive research project completed two decades ago (Sundström 1995).

\section{Contributions to flammability: design (or construction)}

Depending on the design, and regardless of the amount of combustible material used, fire growth may be affected by the presence or absence of features such as gaps between major upholstered areas, armrests, tufting, welt cords, and open loop arms. As measured using Cal TB133, a separated seat and back generally results in a lower HRR, because the back may not become involved in the fire (Sundström 1995; Grand et al. 1994; Damant \& Nurbakhsh 1994). Also, chairs with large gaps between the seat and the back are generally of a more functional design and contain less fuel. On the other hand, chairs with a separated seat and back provide a gap through which the flames from an intensely burning seat can readily reach the back support and accelerate flame spread. Upholstered chairs with no gap between the seat and the back generally contain more fuel and flames remain confined within the structure, thereby assisting fire growth. More luxurious upholstered chairs with armrests present a greater fire hazard, primarily due to the greater amount of flammable material and secondarily because the armrests can facilitate more radiative feedback to the seat, which can result in intense burning. The effect of tufting and welt cords depends on the type of combustion. In the case of smoldering fires, tufting and welt cords act as significant heat sinks, whereas for flaming combustion they act as flame arrestors.

Upholstered furniture in which the upholstery is close to the ground (e.g., furniture with dust covers or short legs), result in rapid fire development and high $\mathrm{HR}$ values (Grand et al. 1994). This is especially true if the furniture materials generate molten polymer drips (e.g., 
PUF and some thermoplastic fabrics), as this may result in pools of molten/degraded polymer that can easily ignite to form a pool fire, which can accelerate burning.

\section{Contributions to flammability: cover fabrics}

Unlike mattresses, where the ticking fabric is more of an afterthought, for residential upholstered furniture the cover fabric is critical to the consumer since it is primary component with aesthetic attributes. To satisfy the large breadth of consumers' preferences, the cover fabric for a given design may be available in a large variety of materials, patterns, and colors, each of which impacts upholstered furniture flammability (Ohlemiller \& Gann 2002; Sundström 1995; Forsten 1994; Damant et al. 1983; Memorandum to D 2004; Coles 2000). For example, the European study, the Combustion Behavior of Upholstered Furniture (CBUF), showed that the cover fabric is the controlling element in small open flame ignition (e.g., from a candle) of upholstered furniture (Sundström 1995). Since the completion of the CBUF study, covering fabrics have changed significantly. This is expected to impact upholstered furniture flammability (Coles 2000; Damant 1995). Modern fabrics are generally constructed of blends of thermoplastic and regenerated cellulosic fibers, which are known to provide better durability and aesthetics, but in some cases, at the expense of flammability. Ohlemiller (Ohlemiller \& Gann 2002; Ohlemiller \& Shields 2008) observed that some thermoplastic fabrics, depending on fabric structure, may split open thereby enabling the underlying components such as PUF and polyester wrap to participate in the fire. This resulted in a rapid increase in HRR and fire growth. To mitigate the increased flammability caused by these covering fabrics, fire blocking technologies were used in this study to delay ignition of the underlying components, thus allowing thermoplastic fabrics to be used while still complying with flammability regulations (Ohlemiller \& Gann 2002).

\section{Fire blocking technologies for soft furnishings}

The purpose of fire blocking technologies is to reduce the flammability of soft furnishings by preventing or delaying direct flame impingement and heat transfer from the flames or molten polymer to the core components. In addition to fire/flame resistance, other desirable properties of fire blocking materials include good handle and drape properties (which impact comfort), durability to wear and tear, cleaning, etc. (which impact service life), and neutral color (which may impact covering fabric appearance, especially for materials under white mattress tickings). As indicated earlier, the flammability behavior of soft furnishings is exceptionally complex because of the large number of variations in materials, construction, and geometries. As a component of a consumer product, fire blocking materials must be cost-effective and not negatively impact the aesthetics, comfort, and durability of the soft furnishings. The number of fire blocking technologies (woven and nonwoven fabrics, FR coatings, and FR PUF) available is quite large to accommodate the requirements of consumers, manufacturers, and regulatory agencies.

\section{FR Mechanisms: passive and active modes}

Fire blocking technologies operate by two broad, not mutually exclusive modes: passive and active (Nurbakhsh \& Mc Cormack 1998). As the term suggests, passive fire barriers are predominantly non-reactive and do not become chemically involved in the flames. Their effectiveness derives from serving as a physical and/or thermal barrier between some or all of the fuel and the potential ignition source. These passive technologies prevent or delay the ignition of interior cushioning materials; however, they do not prevent burning of the outer cover fabric. Passive fire barriers are usually made from inorganic or inherently fire resistant organic fibers. Inherently fire resistant fibers used in this technology have high heat capacity and undergo an endothermic phase change in the presence of heat.

Active fire barriers have a chemical effect on the fire. Active barrier materials, not only prevent the ignition of interior cushioning material but can extinguish the flames from the ignition source and prevent the outer upholstery from burning. The chemical activity of active fire barriers can be in condensed phase (enhanced char formation), gas phase (flame suppression, flame quenching and/or intumescence) or both. They can suppress the flames from the ignition source, prevent the outer upholstery from burning, and prevent the ignition of interior cushioning material by forming char barrier. This essentially lowers the temperatures in a fire and reduces the generation of harmful smoke and gases (Damant 2009). Active technologies generally use combinations of fibers and/or coatings of fabrics, or PUFs with gas-phase-active FR for flame suppression or quenching. In general, passive technologies are good inhibitors of smoldering combustion, whereas active technologies suppress flaming combustion by altering either decomposition or oxidation reactions (Wakelyn et al. 2005).

\section{Barrier fabrics}

Barrier materials are usually textiles that take the form of either an individual component or a layer within a composite of laminated layers. Depending upon the type of barrier material selected, a double upholstery process may be required. However, the use of a barrier material may facilitate the exchangeability of outer cover fabrics. Where barrier materials are not used, fire performance may be drastically affected by generic changes, cover fabrics, and other furniture components. In addition, the use of barrier material may result in other trade-offs. For 
example, highly FR-and more expensive-cushioning materials may not be required. Also, FR treatments of cover fabrics may be unnecessary where appropriate fire blockers are used.

Placed on the surface or between components, barrier materials limit the product involvement in a fire by preventing and/or significantly delaying the ignition of a cover fabric and core materials, lowering the heat release rate, reducing the rate of flame spread and/or extinguishing the flames (Damant 1996; Schumann \& Hartzell 1989; Damant GH. et al. 1994). Often these barrier materials are placed between the exterior cover fabric and the first layer of the cushioning material in the furnished article. In order to meet specific flammability standards, more than one fire blocking technology may be used (Eggestad \& Johnsen 1987).

In general, barrier materials must conform to three different performance criteria: stability, integrity and insulation (Babrauskas 2009). Stability implies that the barrier construction remains, more or less, intact when exposed to a fire or heat source (minimal shrinkage and hole formation). Integrity implies that the barrier material prevents easy pass-through of flames, heat, and volatiles (either through the barrier material itself or its char). Insulation refers to a minimal change in temperature of the unexposed face due to heat transfer through the barrier material. Minimal char shrinkage and retention of non-zero char tensile strength are other key factors in good fire resistance.

The barrier properties of a textile mainly depend on the fabric structure, the yarn construction, and the physical and chemical structure of the char resulting from a fire. The chemical and physical structure of the char determines the resistance to char oxidation. The fabric structure also determines the degree of air entrapment in the char. It is the char that often serves as the actual barrier between flames and the vulnerable contents of a soft furnishing product. Such chars are prone to oxidation during flame exposure, which effectively erodes the barrier, giving it a finite period of protection. This protection period depends on the nature of the organic fiber, minor contaminants in the fiber, the char mass per unit area and the temperature at which the char is exposed (Horrocks 1996).

\section{Barrier fabric types}

As mentioned earlier, barrier materials used in soft furnishing applications are found in various forms. Generally, highloft, nonwoven fiber battings are used in residential mattress applications, whereas coated or laminated textiles are more common in institutional and upholstered furnishing applications. Types of barrier fabrics used in soft furnishings are mainly influenced by end user applications and cost. Structure, thickness, area density, and fiber blends of commercially available barrier materials used in soft furnishings are provided in Table 1. In this section, various fire blocking technologies are discussed with respect to material type, fiber content, and fire blocking mechanisms.

\section{Woven barrier fabrics}

Woven fabrics are generally more robust compared to their non-woven and knitted forms. One of the most important requirements of the upholstery manufacturing process is the stitching or sealing of the edges. For the barrier fabrics to be more efficient, the seams and stitches should remain intact even when exposed to thermal and mechanical stresses. This aspect of barrier fabrics is discussed in greater detail in the following Sections.

\section{Structure}

Woven fabrics have good mechanical properties and retain dimensional integrity even when exposed to heat and/or flame. The interlacing structure of warp and weft holds the decomposition products in place and eliminates the physical shrinkage of char. However, for openweave structures in barrier applications, the volatile gases from the heated PUF can easily find their way towards the flame, resulting in sustained burning. The situation is worse when the cover fabrics are thermoplastic, as the molten thermoplastic penetrates through the open weave structure and ignites the PUF core. For woven barrier fabrics to be effective, they must have a heavyweight construction (e.g., $300 \mathrm{~g} / \mathrm{m}^{2}$ ), as the higher density fabric can prevent escape of pyrolysis gases and/ or penetration of molten polymer (Ohlemiller \& Shields 1995). The trade off is that higher area density and heavier weight can negatively impact the handle and drape properties, thereby affecting the formability, aesthetic, and comfort properties of the upholstered product.

\section{High performance char forming fibers}

In addition to fabric construction, fiber type is also critical to the attributes of barrier materials. Inherently fire resistant fibers (e.g., fiberglass, aramids, melamines, polybenzimidazole (PBI), novoloids, pre-oxidized polyacrylonitriles and carbon fibers) are char forming fibers with high mechanical strength (Bourbigot \& Flambard 2002) that can be used for manufacturing barrier fabrics. Fabrics constructed from these inherently flame retardant fibers are expensive, and they are frequently used in high-performance applications (e.g., aircraft seating, seating in other mass transport vehicles and public buildings). Fire barrier fabrics constructed of fiberglass are very effective at preventing an ignition source from reaching the PUF core, as the fiberglass is a high char-forming fabric with strong structural integrity (US Patent Application 
Table 1 Examples of commercially available barrier materials for soft furnishings

\begin{tabular}{|c|c|c|c|c|c|}
\hline & Structure & Constituent fibers & $\begin{array}{l}\text { Thickness, } \\
\mathrm{mm}\end{array}$ & $\begin{array}{l}\text { Area density, } \\
\mathrm{g} / \mathrm{m}^{2}\end{array}$ & Application \\
\hline \multirow[t]{10}{*}{ Non-woven } & \multirow{2}{*}{$\begin{array}{l}\text { Thermally bonded } \\
\text { highloft }\end{array}$} & FR rayon/polyester & \multirow[t]{2}{*}{$10-15$} & \multirow[t]{2}{*}{$150-250$} & \multirow{9}{*}{$\begin{array}{l}\text { Residential } \\
\text { mattresses }\end{array}$} \\
\hline & & Basalt-based fiber/FR treated cotton/polyester & & & \\
\hline & $\begin{array}{l}\text { Needlepunched } \\
\text { stratified }\end{array}$ & Inherent FR fibers & - & - & \\
\hline & \multirow[t]{2}{*}{ Needlepunched } & FR Rayon/Polyester low melt synthetic fiber & - & \multirow[t]{3}{*}{$225-245$} & \\
\hline & & Boric acid treated cotton & - & & \\
\hline & $\begin{array}{l}\text { Needlepunched } \\
\text { stratified }\end{array}$ & $\begin{array}{l}\text { Boric acid treated cotton/polyester fiber + FR } \\
\text { rayon/polyester }\end{array}$ & - & & \\
\hline & Needlepunched & \multirow[t]{2}{*}{ FR rayon/polyester } & $2-8$ & $140-240$ & \\
\hline & Stitchbond & & 0.9 & 180 & \\
\hline & Needlepunched & FR rayon & - & - & \\
\hline & Non-woven & Glass fiber & $10-11$ & $230-260$ & $\begin{array}{l}\text { Non-residential } \\
\text { mattress }\end{array}$ \\
\hline \multirow[t]{2}{*}{ Woven } & \multirow[t]{2}{*}{ Woven } & Glass fiber & $5-6$ & $100-130$ & \multirow{4}{*}{$\begin{array}{l}\text { Upholstered } \\
\text { furniture }\end{array}$} \\
\hline & & $\begin{array}{l}\text { Core spun yarn with glass fiber core and FR } \\
\text { modacrylic sheath }\end{array}$ & - & 169.5 & \\
\hline \multirow[t]{2}{*}{ Knitted } & Knitted & \multirow{2}{*}{$\begin{array}{l}\text { Core spun yarn with glass fiber core and FR } \\
\text { modacrylic sheath }\end{array}$} & - & 186.45 & \\
\hline & Double face knit & & - & 237.3 & \\
\hline
\end{tabular}

20070161312 - Fiberglass fire barrier for mattresses. Filed on January 11 2006). Fiberglass fabrics (woven, knitted or non-woven) are often used as substrates for FR coating or laminating FR layers. The disadvantage associated with fiberglass flame barriers is poor durability (due to glass-toglass abrasion) and lack of resiliency (Dry et al. 2006).

\section{Fiber blends}

The main disadvantage of inherently FR fibers is their cost. To reduce fabric cost and still maintain performance, manufacturers construct fire barrier fabrics as blends with other lower cost fibers. Fiber blending may occur before or during yarn formation stage. The less expensive thermoplastics polymers are not ideal candidates for barrier materials. Barrier materials made solely from thermoplastic fibers often melt, shrink, and crack open (Ohlemiller \& Shields 1995). Once there are openings in the barrier material the flames propagate to the PUF core, and the soft furnishing will burn as if there was no fire barrier. However, this melting can provide an advantage if the thermoplastic is combined with a network support fabric (e.g., fiberglass matting or any char forming fiber fabric), as the thermoplastic can fill the voids of the network and thereby form a strong and durable fire blocking system (Ohlemiller \& Shields 1995). Another alternative is to use FR thermoplastic fibers in conjunction with non-thermoplastic char forming fibers or thermoplastic fiber fabric backcoated with a char forming FR coating.

\section{Natural fibers}

Barrier materials constructed of natural fibers (e.g., cotton) often produce a fire blocking char upon exposure to heat and/or flames. Cellulosic fabrics require chemical treatment (e.g., boric acid) in order to yield excellent fire resistance. FR treatment can be applied to the final fabric as a coating, or FR chemicals can be introduced during fiber formation to alter the polymer structure (e.g., FR rayon fiber with polysilicic acid backbone). The FR rayon is generally used in upholstered furniture applications when combined with modacrylics, aramids, and wool fibers. For mattress applications, FR rayon fibers are usually blended with polyester fibers to form highloft battings. When exposed to heat, the FR rayon decomposes endothermically and forms a silicate-containing protective char (Horrocks 1996). The low melt polyester fiber melts holds the protective char in place (Dennis ML 2999).

\section{Core spun yarn}

Another fire blocking technology uses core spun yarn to produce barrier materials. Core spun yarn (also known as core-sheath yarn) begins with an inherently fire resistant fiber core (e.g., glass). This core is then coated with a less expensive material (e.g., polyester) that is primarily responsible for the aesthetic and comfort properties. The thermally stable core maintains the structural integrity and provides a woven framework (grid) for the char layer (lattice) formed by the thermal decomposition of the sheath fiber. This type of "grid/lattice" structure 
(http://www.alessandrayarns.com/about.html 2999) provides the physical barrier that prevents flame penetration into the more flammable cushioning layer as discussed earlier. The composition of the core and sheath can be tailored to satisfy fabric performance requirements. For example, to further improve fire resistance the sheath layer may contain FR, and to improve strength and durability a polyester or polyamide sheath may be used instead of a cotton or polypropylene. Beside barrier fabrics, the core spun yarn may also be used as sewing thread in upholstery.

\section{FR coatings on woven barrier fabrics or cover fabric}

Another approach to improve the fire resistance of a woven fabric is to apply an FR coating to the outer cover fabric or fire barrier fabric. These coatings are attractive to the manufacturer as they can be applied to almost any fiber/fabric type. FR-treated fabrics only retard or delay the spread of flames as long as treatment chemicals are retained in the fabric. FR protection may be lost due to wear and tear. Some FR-coated barrier materials are functional for a short time but have serious drawbacks, including separation of the coating from the knitted substrate followed by balling up under the upholstery fabric and complete disintegration over a short period of time (Anon 2999).

\section{Coating placement}

If the FR coating is applied to the inside face of the cover fabric as a backcoating, there may be little impact to the fabric aesthetics. However, when applied to the outside face or to both sides of the cover fabric, the fabric color, feel, and stiffness may be significantly altered. Although the aesthetics of laminated/coated fabrics may not be as desirable, these fabrics are often used to comply with the more stringent high occupant dwelling flammability regulations (e.g., Cal TB 133, Cal TB 129). In the UK, backcoated FR cover fabrics are considered to take about $80 \%$ of the soft furnishing market (Horrocks et al. 2007). While FR coated cover fabrics self-extinguish and exhibit limited flame spread, they do not perform well when exposed to large ignition sources even for a short duration as they have a tendency to form brittle chars that crack open and expose the more flammable core materials. Research has shown that FR backcoating improves resistance to small flames like match and BS: Crib 5 (17 $\pm 1 \mathrm{~g}$ of wood), but when tested with large ignition sources as in Cal TB 133 or CFR 1633, the increased heat release of the backcoating results in accelerated thermal decomposition of the underlying PUF (Gallagher 1993). As discussed previously, it is these types of unexpected interactions between the components resulting in a synergistic or antagonistic impact on pyrolysis that makes it difficult to predict soft furnishing flammability based on the flammability characteristics of the individual components.

\section{Composition}

A typical FR backcoating formulation used for upholstered cover fabrics consists of FRs (typically halogenantimony-containing compounds), fillers, synergists and application ancillaries (e.g., polymeric resin binder, fabric softeners, and cross linking agents). Halogen-antimony FRs are most frequently used because they are very effective for both synthetic and natural fiber containing fabrics and have relatively low cost (Weil \& Levchik 2008). A halogen-containing polymer, combined with vinyl fluoride and finely dispersed antimony oxide, is commonly used for heavily used applications such as healthcare mattresses and mass transportation seating because it is significantly more difficult for the halogen to leach out when it is bound to a polymer rather than as a small molecule additive (Nazare 2009). A drawback limiting this application is that halogenated polymers often require a plasticizer and softening agents during processing, which can result in antagonistic reactions with other components of furniture (Schumann \& Hartzell 1989) and itself may be a fuel for pyrolysis. Moreover, halogen and antimony containing molecules in backcoating formulations are of major environmental concern and this is currently driving changes in backcoated FR textiles. Other flame retardant strategies that have been explored for FR textiles include removal of heat by using compounds that undergo endothermic phase change and generate water upon heating (e.g. aluminum trihydrate, inorganic and organic phosphorus compounds), decreased formation of flammable volatiles and enhanced char formation (phosphorus- and nitrogen-containing compounds) (Horrocks 2001). Recent developments in backcoating technologies for FR textiles have been reviewed in details elsewhere (Horrocks 1996; Horrocks 2008a).

\section{Composite barrier fabrics}

Barrier materials created by bonding a highly fire resistant "layer" to one of the textile components are also commonly used in upholstered furniture. Bonding is generally accomplished by mechanical processes such as stitch bonding or needle punching, or thermal (heat bonding) processes. Adhesives can also be used for laminating various layers of barrier fabrics.

Composite or laminated fabrics offer two advantages. First, they eliminate the labor involved in sequential upholstering of fabric layers, and second, they prevent exposure of underlying cushioning materials by 'crackopening'. When the multi-layered barrier fabric is exposed to flames, the heat is taken away by the outer coating or layer of the composite fabric, leaving the underlying substrate to which the coating or outer layer is laminated 
intact and preventing the involvement of underlying cushioning materials in the fire. For example, when a glass fiber fabric coated with polyvinyl chloride is exposed to flames, the polymer does not shrink away from the underlying glass fiber fabric. Instead, it softens and flows into the interstices of the glass fiber fabric. Laminated/coated fabrics eliminate the air space between the layers of barrier fabric and maintain the aesthetics of the exterior fabric while still providing better fire performance (Schumann \& Hartzell 1989; Decabromodiphenylether 2005).

Another example of a fire resistant laminated fabric is an aluminum foil liner constructed of a very thin layer of aluminum sandwiched between a woven fiberglass and spun fiberglass. Since these types of barrier fabrics are quite thin and flexible, they do not impart stiffness to the upholstered product when placed between the fabric and the filling. Thin layers of FR PUF laminated or backcoated onto various textile substrates are in use as fire barriers in mattresses and upholstered furniture. Their major drawback is cost, as they can be an order of magnitude more expensive than other fire blocking technologies.

Multi-layered barrier fabric structures comprised of fabrics made from layers of structural char-forming, heat-absorbing and inherently fire resistant fibers have also been suggested (Small \& Walton 2007; Ma 2007). Such multi-layered structures have fewer open cracks and holes when exposed to open flames.

\section{Nonwoven barrier materials}

Nonwoven fabrics are low density fabrics characterized by a high ratio of thickness to weight per unit area (Parikh et al. 2003). Intermingled fibers are compressed or densified by the process of either needle-punching, stitchbonding or thermal-bonding. The term nonwoven is used in the textile manufacturing industry to denote fabrics that are neither woven nor knitted. Nonwoven barrier materials are generally less expensive than woven and knitted barrier fabrics. However, disadvantages associated with their manufacturing techniques, such as uneven blending, regions with uneven area density etc., affect their performance as barrier materials. Nonwoven materials typically lack strength (tensile and bursting) unless densified or reinforced by a backing. Due to their structural characteristics, nonwovens also have challenges associated with their mechanical performance and thermal shrinkage when exposed to heat. Thus, good quality control measures are critical during manufacturing.

\section{Loft}

The weight or thickness of a nonwoven fabric is reported by a term called loft. Highlofts have low density with a greater volume of air than fiber. Generally, highlofts with a thickness ranging from $7 \mathrm{~mm}$ to $51 \mathrm{~mm}$ and a basis weight of $75 \mathrm{~g} / \mathrm{m}^{2}$ to $375 \mathrm{~g} / \mathrm{m}^{2}$ are preferred for soft furnishing applications. When exposed to an open flame ignition source, highloft barrier materials containing charforming fibers form a thick char that blocks the flow of oxygen and volatile decomposition gases and also slows heat transfer by creating an effective thermal insulation barrier (Hendermann \& Bridges 2006). Highloft high porosity structures also inhibit flame spread. An alternative to a highloft material is compressed layers of a flame retardant nonwoven material that expand when exposed to heat and provide a thermally thick barrier (Weil \& Yang 2008).

\section{Fiber type}

Nonwoven battings/barrier materials of inherently fire resistant fibers and natural and/or synthetic fibers have been reported (Horrocks 1996; Hendermann \& Bridges 2006; Shanley et al. 1994; Mater 2007; Hendermann 2004; Horrocks et al. 1994). These blends are designed to withstand extended periods of exposure to open flame and to prevent the underlying materials from igniting. The proportion and the type of fire resistant fibers used depend on balancing cost and flammability performance of the soft furnishing. In addition to the cotton and typical synthetic polymers already discussed (e.g., polyester), battings have also been constructed using other natural fibers such as flax, jute, hemp and wool, but their use has been limited by difficulties in processing (Flambard et al. 2002; Kozlowski et al. 2002; Kozlowski et al. 1999; Flambard et al. 2005; Knoff \& Hall 2006).

\section{Cotton treated with boric acid}

Nonwoven cotton battings treated with boric acid have been used for many years as fire barriers in soft furnishings products, especially mattresses (Wakelyn et al. 2005). These materials are the least expensive FR barrier materials available on the market, since they usually contain cotton fibers that are procured from textile mills as by-products or waste products. Boric acid catalyzes dehydration reactions of the oxygen-containing fibers and facilitates char formation (Dombrowski 1996). When exposed to an open flame, the boric acid decomposes endothermically to release water and cool the flame. The glassy coating formed by the decomposition of boric acid suppresses the release of volatile species from the underlying fuel and acts as an oxygen barrier, thereby preventing further oxidation of volatiles. Because of the low intrinsic toxicity, boric acid and borates can be safely used in consumer products (Toxicological Risks of Selected Flame Retardant Chemicals et al. 2000). However, boric acid treatments may have problems associated with durability to soaking, chalking, color change and undesirable texture.

In soft furnishings products, nonwoven FR cotton batting is helpful in meeting various flammability requirements, 
including the cigarette ignition ASTM D5238-98 test (sandwich batt test), the open flame Cal TB 117 test (both vertical and horizontal burning) and the large-scale Cal TB 129 and 16 CFR 1633 tests (Wakelyn et al. 2003). Various methods to enhance both smoldering and flaming resistance of cotton battings have been explored. Barrier materials constructed of cotton blends with inherently flame retardant fibers (e.g., FR-modacrylic, FR-polyester, and FR-viscose) enable soft furnishings to comply with various cigarette resistance and open flame resistance regulations. The slow combustion of cotton battings in soft furnishings, especially mattresses, is the critical element that allows sufficient egress time for humans to react to the fire. The disadvantage, however, is that these barrier materials are very bulky and hence rarely used in upholstered furnishings.

\section{Polyester fiber}

Polyester fiber battings, commonly used in upholstered seats, provide a significant barrier effect when tested with smoldering cigarette ignition (Gandhi \& Spivak 1994). However, it fails to protect the underlying cushioning material when an open flaming ignition source is used (Damant GH. et al. 1994). The polyester fiber melts away from the smoldering cigarette and extinguishes, whereas the polymer melt burns in the presence of flaming ignition. Once ignited, the molten polymer burns vigorously, resulting in substantial weight loss and increased temperature of the system. Thus, the polyester fiber batting acts as an additional fuel and the whole system fails. Recent studies on the flammability of cushions with polyester fiber wraps (low loft batting) in our laboratories have shown that the presence of polyester wrap increases the PHRR when compared to analog systems without polyester fiber wrap (Davis et al. 2009). This study suggests that, regardless of the type of FR-PUF and/or cover fabric, polyester fiber promotes the composite system to burn vigorously.

\section{Organic and inorganic fiber blends}

Horrocks (Horrocks et al. 1993) developed a novel fire barrier fabrics comprised of a flexible nonwoven core containing both organic and inorganic fibrous components. The core is constructed such that it permits flexibility at both low and high temperatures. When exposed to temperatures below $500^{\circ} \mathrm{C}$, the engineered fabric accommodates expansive forces generated by the developing intumescing char component by increasing in volume and thickness while still maintaining its structural integrity and flexibility. These composite structures have a unique flame and thermal protective behavior that enables the fabric to respond to an incident heat flux in a manner that initially enhances its protective property following intumescent char formation. At higher temperatures, this protective property is reduced but not destroyed, as it is in the case of high performance fabrics containing aromatic and carbonized fibers. These barrier materials, however, were not tested for open flame ignition performance.

The latest development in nonwoven barrier fabrics is the siliconized thermally bonded highloft barrier material. The siliconized highloft is a blend of three different types of siliconized fibers (e.g., Basofil ${ }^{\circledR}$, Tencel ${ }^{\circledR}$ and Protex ${ }^{\circledR}$ ) held together with a low-melt polyester (Hendermann \& Bridges 2006). Each component of the blend provides a specific and necessary functionality to the barrier material. The siliconized melamine fibers provide a non-shrinking form of carbon, whereas the regenerated cellulosic fiber improves the softness and water repellency of the blend. The regenerated cellulosic fiber is very cost effective and can be used to increase the bulk of the product. Siliconized modacrylic fiber, when used in an appropriate blend ratio, can reduce the local oxygen content within the barrier during a fire, thereby prolonging char oxidation. The low melt polyester provides resiliency to the barrier, and its strong thermoplastic character helps to maintain the structural integrity of the char formed.

\section{Polymeric foams}

Typically, soft furnishings contain standard PUF as the filling/cushioning component. The PUF is inherently flammable unless treated with an FR additives (e.g., halogen and halogen-phosporous compound such as Tris(1-Chloro-2Propyl) Phosphate (TDCPP)) which are traditionally gasphase acting FRs (Kim et al. 2011). Over the past decade many FRs have been banned due to environmental, health, and safety (EHS) concerns, and many are under scrutiny (Environmental Protection Agency 2010; Kemmlein et al. 2009).

An innovative and potentially green FR approach with potentially strong commercial viability is to create a fire blocking armor on the PUF or fabrics using a thin polymeric coating containing fire retardants (to be discussed in the Future Trends on Fire Blocking Technologies section). Other halogen-free FRs now in the research stage are PUF containing a combination of ammonium polyphosphate, pentaerythritol and melamine (an intumescent coating) and PUF impregnated with graphite (Singh \& Jain 2009).

\section{Lower flammability polymer}

Another approach to reduce the flammability of foam is to use a foam based on a lower flammability polymer. Intrinsically FR foams (e.g., polyimide foam) are more commonly used in higher risk environments (e.g., aircraft and spacecraft seats) where their higher cost is justified by the additional fire safety necessary to comply with strict flammability regulations. These foams may be harder to ignite, have lower HRR, have higher thermal stability, etc. For example, a polyester foam was evaluated 
by CPSC in the early 1990s as resistant to cigarette ignition. This foam exhibited superior resistance to smoldering ignition sources, but was more easily ignited by open flames (as compared to PUF) (Damant \& Nurbakhsh 1992). Polyester foam is not commonly used in soft furnishings due to higher cost and durability issues (e.g., hydrolytic degradation).

\section{Encapsulation}

$\backslash$ A cost-saving approach is to create a composite of a PUF core encapsulated by one of these intrinsically FR foams. For example, Hashish (Hashish et al. 2003) evaluated a polyimide foam as a fire barrier for spacecraft cushion material. When tested by cone calorimetry, the application of polyimide foam layers over standard PUF increased the minimum heat flux for ignition of flammable PUF from $27 \mathrm{~kW} / \mathrm{m}^{2}$ to $48 \mathrm{~kW} / \mathrm{m}^{2}$. This ignition risk reduction was sufficient to enable the noncompliant PUF to pass the targeted regulations. Inclusion of polyimide foam layers also significantly reduced the PHRR, mass loss rate (MLR), and the generation of smoke and carbon monoxide. Carboxylated chloroprene foams are also commonly used to encapsulate the PUF core or as a fabric backing. Chloroprene foams are high density foams which are generally specified for public transport applications. They generally act as active fire barrier materials.

\section{Performance of fire barriers}

Successfully achieving the desired level of fire protection requires appropriate matching of barrier materials to the desired characteristics of the soft furnishing. This selection is generally a process of trial and error due to significant measurement science gaps. Below are a few examples demonstrating the complexity that makes a priori selection of fire barrier materials difficult.

\section{Impact of barrier materials on flammability of mattresses Innerspring mattresses}

The impact of barrier materials on the flammability of innerspring mattresses with different filling materials is shown in Figure 1 (Nurbakhsh \& Mc Cormack 1998). Regardless of the filling type, these innerspring mattresses were able to pass the open flame ignition test for mattresses (TB 129 (Technical Bulletin 129 1992)) designed for high occupancy dwellings, with a $100 \%$ success rate using a fire barrier (e.g., fiberglass fabric). The test criteria for passing TB 129 limits maximum heat release rate to $100 \mathrm{~kW}$, total heat release in the first $10 \mathrm{~min}$ of the test to $25 \mathrm{MJ}$ and weight loss to $1.36 \mathrm{~kg}(3 \mathrm{lb})$. This essentially requires complete protection of cushioning materials from heat and flame. Without the fire barrier, the same mattress construction had inconsistent TB 129 performance with the degree of failure depending on the type of filling material. For example, PUF innerspring mattresses had a success rate of 44\%, signifying four passes out of 9 tests (Nurbakhsh \& Mc Cormack 1998). The cotton batting/PUF innerspring mattress and polyester fiber batting/cotton felt/PUF innerspring mattresses yielded a success rate two times greater at approximately $88 \%$. Innerspring mattresses with a polyester fiber batting combined with an insulator pad and PUF or cotton batting

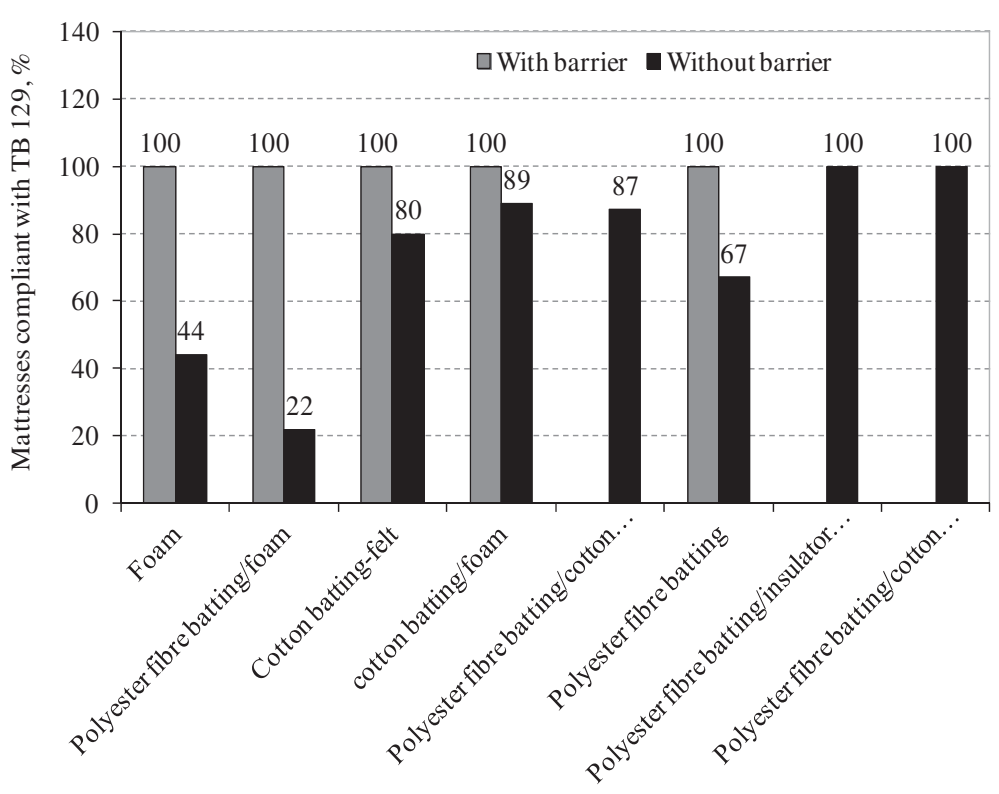

Figure 1 Comparison of full-scale flammability test results for innerspring mattresses with different types of filling materials in the presence or absence of fire barrier materials (Nurbakhsh \& Mc Cormack 1998). 
had a 100\% TB 129 success rate without the need for a fire barrier material.

\section{Solid core mattresses}

In this same study, the researchers determined that solid core mattresses passed TB 129 without using a fire barrier material (Nurbakhsh \& Mc Cormack 1998). This is presumably a result of restricted airflow in a solid core mattress, which restricts the entrainment of oxygen needed to sustain pyrolysis. This suggests that under the right constructions and with the right combination of materials it may be possible to pass TB 129 without using a barrier material. However, this does not necessarily provide a product that is desirable by the manufacturer or consumer (e.g., it may not be comfortable, attractive, or cost-effective).

\section{Interaction with tickings}

Tickings perform differently in the presence or absence of fire barrier materials. A majority ( 80\%) of mattresses with a polyvinyl chloride (PVC) ticking pass the TB 129 without using a barrier fabric because PVC tickings are active fire barriers with self extinguishing behavior (Nurbakhsh \& Mc Cormack 1998). Approximately 20\% mattresses with PVC coated ticking fail due to antagonistic reactions of highly plasticized PVC coated fabrics with other components of upholstery. Mattresses with cotton/ fiberglass ticking do not require an additional fire barrier material to protect the underlying cushioning layer either. In this case, the cotton/fiberglass ticking acts as a passive fire barrier and physically prevents flame and heat transfer to the underlying cushioning layer. On the other hand, mattresses with cotton ticking certainly require a fire barrier in order to pass the open flame test. This is partly because cotton is extremely flammable and cotton tickings burn with a higher rate of flame spread, thereby exposing underlying cushioning layers to the open flames.

\section{Institutional vs. residential mattresses}

The materials and constructions discussed above for passing TB 129 are generally used for institutional mattresses. For institutional mattresses, fire performance is more important than comfort and aesthetics. However, polyvinyl tickings, fire barriers with fiberglass substrates, and solid core mattresses with densified polyester batting are not preferred choices for residential mattresses due to cost, comfort and aesthetics. Unlike institutional mattresses, comfort and aesthetics are of primary importance in the case of residential mattresses; hence, fire performance must be achieved while still maintaining the comfort and aesthetics. For this reason, highloft barrier materials are more commonly used as fire barriers in residential mattresses. Ticking with polyester or polyester blends that are generally used in residential mattresses behave very differently in presence of fire barriers. The effects of melting and dripping can have a varied impact on the flammability of a mattress. Data for compliance to 16 CFR 1633 for residential mattresses with highloft or other newly engineered barrier materials are currently not available. Several polyester blend tickings are being currently investigated and their fire performance with and without fire barriers is being studied in our laboratories.

\section{Impact of barrier materials on flammability of upholstered furniture \\ Cover fabric}

The impact of a fire barrier materials on the flammability of upholstered seating has been extensively investigated by Damant et al. (Damant 1996; Damant \& Nurbakhsh 1994), who used the Cal TB 133 test for comparison. The test criteria for passing TB 133 limits maximum heat release rate to $80 \mathrm{~kW}$, total heat release in the first $10 \mathrm{~min}$ of the test to $25 \mathrm{MJ}$ and weight loss to $1.36 \mathrm{~kg}(3 \mathrm{lb})$. The test also has smoke and carbon monoxide limitations (Technical Bulletin 133 1991). With a fire barrier material, most cover fabrics will have a greater than $85 \%$ passing rate, which is $10 \%$ to $50 \%$ better than that achieved without using a barrier material. However, the level of confidence in passing the Cal TB 133 test depends on the type of cover fabric. In the case of poorly performing cover fabrics, the use of barrier material is essential to pass $\mathrm{Cal}$ TB 133 test (Figure 2). Using a nylon/polyester or polyolefin cover fabric with a fire barrier provides a chance of passing of $70 \%$ (3 out 10 replicates failed); whereas chairs with polyester or wool/nylon cover fabrics had a higher chance of passing (90\%).

In a separate study (Memorandum to D 2004), a range of barrier materials and cover fabrics used in upholstered furniture were tested in a mockup seating arrangement, and their individual as well as combined responses to cigarette ignition, small open flame, and wooden crib tests were reported. A description of the cover fabrics is provided in Table 2, with flammability results separated by ignition source and barrier fabric type summarized in Additional File 1: Table S1. In the absence of a fire barrier fabric, all the cover fabrics passed the smoldering ignition test (cigarette ignition source) but failed the small open flame (butane gas flame ignition source) and crib ignition tests. The exceptions to these results were FR polyester and silk cover fabrics, which self extinguished once the butane flame and burning crib were removed. In the absence of a cover fabric, all the barrier fabrics passed the smoldering test, butane flame and crib ignition tests, except for the $100 \%$ cotton, which only passed the cigarette and small open flame 


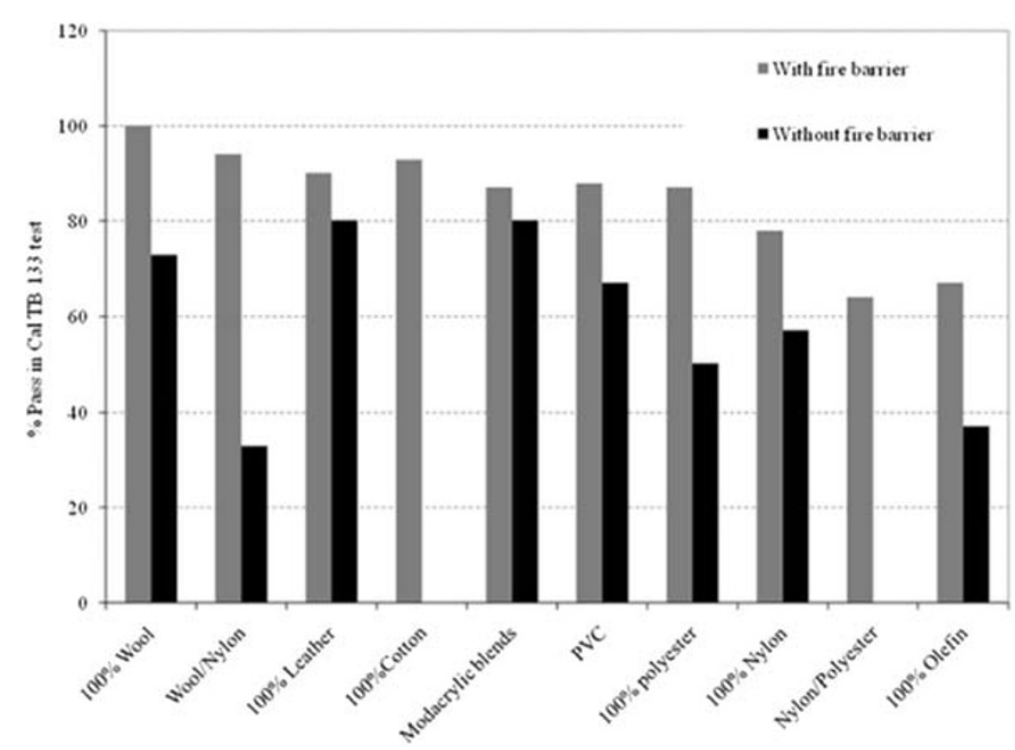

Figure 2 Impact of fire barrier fabrics on performance of upholstered chair (with different cover fabrics) in full-scale flammability testing (Damant \& Nurbakhsh 1994).

ignition tests. This data suggests that the type of barrier material appears to impact the ability of the cover fabric to pass both the smoldering and open flame ignition tests. For example, the $100 \%$ cotton (cover fabric II) failed the butane flame ignition tests when combined with all barrier materials except the $100 \%$ cotton. The same cover fabric $(100 \%$ cotton) failed the smoldering ignition tests for the $100 \%$ cotton $\left(220 \mathrm{~g} / \mathrm{m}^{2}\right)$, the novoloid, and the melamine based barrier fabrics. Another example is the barrier fabric that contain inherently flame retardant fibers (e.g., polyaramids, phenol-aldehyde, melamine and modacrylic), which were resistant to all three ignition sources, although their fire performance was altered by the type of cover fabric. Most barrier fabrics tested failed the cigarette ignition test in the presence of $100 \%$ cotton cover fabrics (the cotton twill and cotton corduroy). This study concluded that some cover/ barrier fabric combinations appear to be effective in protecting the PUF from a flaming ignition source but do not always provide the same protection from a smoldering ignition source. This is derived from the fact that none of the cover fabrics ignited from a smoldering cigarette when tested by themselves, yet ignition occurred when the barriers were combined with certain cover fabrics. Trapping of heat below the barrier fabric may cause exothermic reaction in the PUF leading to ignition.

\section{Barrier effect mechanisms}

In a separate study, Ohlemiller (Ohlemiller \& Shields 1995) concluded that the barrier effect is more physical than chemical. In this study, the researchers measured the impact of HRR by changing the barrier material and covering fabrics over a Cal TB 117 complaint PUF (Glossary of flexible Polyurethane foam technology \& Joint Industry Foam Standards and Guidelines SECTION 15.0 Published: July

Table 2 Performance and properties of various cover fabrics in cigarette ignition and small open flame tests (Memorandum to D 2004)

\begin{tabular}{|c|c|c|c|c|c|}
\hline Sample description & Fiber content & $\begin{array}{l}\text { Fabric } \\
\text { construction }\end{array}$ & $\begin{array}{l}\text { Area density, } \\
\left(\mathrm{g} / \mathrm{m}^{2}\right)\end{array}$ & $\begin{array}{l}\text { Cigarette } \\
\text { ignition test }\end{array}$ & $\begin{array}{l}\text { Small open } \\
\text { flame test }\end{array}$ \\
\hline Cover Fabric I & 100\% FR Polyester & Plain weave & 220 & Not Tested & $\sqrt{ } / \mathrm{P}$ \\
\hline Cover Fabric II & $100 \%$ cotton & Twill & 413 & $x$ & $\sqrt{ } / F$ \\
\hline Cover Fabric III & $100 \%$ cotton & $\begin{array}{l}\text { Pile weave } \\
\text { corduroy }\end{array}$ & 332 & $x$ & $\sqrt{ } / F$ \\
\hline Cover Fabric IV & $100 \%$ Cotton & Plain weave & 220 & $x$ & $\sqrt{ } / F$ \\
\hline Cover Fabric V & 56\%Rayon/34\%polyester/10\%cotton & Jacquard & 349 & $x$ & $\sqrt{ } / F$ \\
\hline Cover Fabric VI & $60 \%$ acetate $/ 40 \%$ cotton & taffeta & 136 & $x$ & $\sqrt{ } / F$ \\
\hline Cover Fabric VII & 100\% silk & Plain weave & 125 & $x$ & $x$ \\
\hline Cover Fabric VIII & $57 \%$ acrylic/31\%polyester/12\% olefin & Plain weave & 303 & $x$ & $\sqrt{ } / F$ \\
\hline
\end{tabular}

$\mathrm{X}:$ no ignition, $\sqrt{ } / \mathrm{P}$ : ignition but passes the test, $\sqrt{ } / \mathrm{F}$ : ignites and fails the test. 
1994). The PUF/barrier material/cover fabric specimens were tested in the cone calorimeter at $35 \mathrm{~kW} / \mathrm{m}^{2}$ heat flux. The cone data indicates that woven glass fabric yields a lower averaged HRR regardless of the cover fabric type than do aramid fiber fabric or knitted fabric with a glass and charring fiber blend (Figure 3). Similar results were obtained when composites were tested without a cover fabric. A knitted fabric with a glass fiber blend used as a fire barrier fails to protect the underlying PUF from heat. In this case, the flames from the burning cover fabric propagate through a relatively open knitted structure and ignite pyrolysis gases from the heated PUF, whereas the tightly woven glass fiber fabric significantly prevents the escape of pyrolysis gases from the underling PUF. For all the fabrics tested in this study, the HRR (not shown here) for nonwoven aramid fabric and knitted glass fabric showed two distinct peaks: the first peak was dominated by the cover fabric and the second peak by the PUF. The testing of woven glass fabric invariably showed a single peak, from the burning of the cover fabric alone. Thus, not all fire barriers succeed in protecting the PUF from the heat. The level of protection depends on heat transfer properties of barrier fabric and cover fabric which are essentially governed by the fiber type and construction of the barrier and cover fabric.

\section{Performance assessment of fire barrier materials Failure mechanisms: shrinking and char strength}

One of the failure mechanisms for fire barrier materials is the stress-induced separation/splitting of barrier that results in exposing the cushioning materials of the soft furnishing to high temperatures and flames. When exposed to heat and/or flames, the barrier material undergoes chemical and/or physical changes (e.g., dissipation of heat, release of $\mathrm{FR}$, and formation of a protective char), and that may cause the barrier to shrink, become stiff and/or brittle, and/or become thinner. The unexposed/unshrunken fire barrier exerts a force on the shrinking char, causing the barrier material to split open. The extent of the physical deformation is affected by the type of barrier material used. For example, a knitted barrier fabric will split open to a greater extent than a woven or nonwoven barrier fabric (Ohlemiller \& Shields 1995). The force that the unexposed barrier exerts on thermally degraded barrier material is dependent on the length and pre-tensioning of the barrier, as well as the "anchoring" forces on the barrier in the specific application. For example, the force seen by an area of barrier material on the top of the mattress may be lower than on the side as a result of the absolute amount of shrinkage caused by the greater length of the spring (unexposed fabric) on the top versus the side. The mattress application of barrier material is complicated by the fact that the material may be sewn tightly to other layers (ticking and back scrim) whose mechanical properties also affect, and potentially dominate, the amount of pulling stress on the barrier material. In addition, the edge conditions, and in particular the extent to which they inhibit shrinkage-induced movement, vary considerably with mattress design.

The situation for upholstered furniture is more complicated, as the barrier material is stretched over a three-dimensional geometry. Thus, the performance of a barrier material in a given type of application may depend appreciably on the specific details of that application as well as on the properties of the barrier material itself. Nonetheless, an important measure of barrier effectiveness is the extent to which it shrinks under heat exposure given the tensile properties of the resulting degraded material. Currently, there are no well defined test methods to determine char strength and shrinkage potential of barrier materials. Some industries determine char shrinkage or hole formation in the barrier material by exposing the specimen to a Meeker burner (Figure 4) for a specified duration. The test is purely qualitative. The chars for some barrier material tested using this method are shown in Figure 5. Nonwoven felts of inherently fire resistant fibers such as para-aramid, melamine and metaaramid form a protective char when exposed to an open flame. Meta-aramid char is more brittle as compared to para-aramid char. The synthetic fiber felts (modacrylic, rayon, and polyester) melt and shrink away from the flame.

\section{Failure mechanisms: thermal degradation}

Another common failure mechanism for fire barrier materials is heat penetration at sufficient levels to cause thermal degradation of PUF and generate highly combustible gases. The barrier material can still be structurally intact (no splitting) while the heat is transferred to PUF. When heated, PUF can collapse to form a pool of molten polymer. ASTM D7140 is a standard test for measuring the thermal penetration performance of barrier material intended to be used in soft furnishings (ASTM D7140 07 Standard test method to measure heat transfer through textile thermal barrier materials 2999). The barrier material is exposed to a well defined and controlled convective (open-flame) heat source for 60 seconds (Figure 6). This test method essentially measures the heat transfer of textile materials and determines whether the heat transferred through the fire barrier material is sufficient to ignite underlying materials.

\section{Test standards: UFAC smoldering ignition test for barrier fabrics}

The Upholstered Furniture Action Council (UFAC) has defined a barrier test method to measure the performance of a barrier material exposed to a smoldering ignition source. The UFAC test method is voluntarily used by many upholstered furniture manufacturers (Upholstery Furniture 


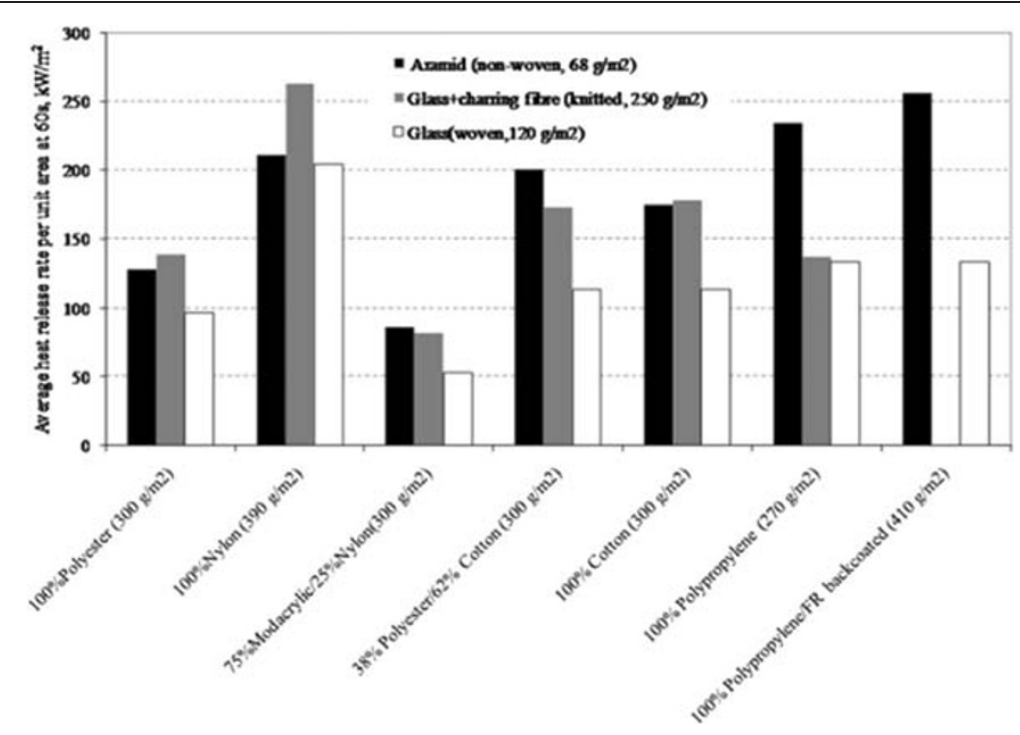

Figure 3 Impact of different cover fabrics and fire barriers on PHRR of composite specimens tested under cone calorimeter $\left(35 \mathrm{~kW} / \mathrm{m}^{2}\right)$ (Ohlemiller \& Shields 1995).

Action \& Central Box 2436). The smoldering ignition assessment is conducted on a mock up composite (Figure 7) and is intended to define the minimum fire barrier performance level (cigarette ignition resistance) necessary to prevent ignition of a standard PUF covered with a smolder prone/ignitable fabric (Class II cover fabric). This test is based on the BS 5852 Part I test method (BS 58522006 Methods of test for assessment of the ignitability of upholstered seating by smoldering and flaming ignition sources 2999) to test the ignitability of an upholstered composite to a smoldering type of ignition source. For barrier materials to pass this pass/fail test, the composite cannot ignite and the vertical char length cannot exceed $38 \mathrm{~mm}$ upward from the crevice (Upholstery Furniture Action \& Central Box 2436). Generally, barrier materials with high area densities and highloft constructions pass this test. ASTM had a barrier component test (now obsolete) to assess the smoldering ignition resistance of cotton battings. The ASTM D 5238 (ASTM D5238 10 Standard test method for smoldering combustion potential of cotton based batting 2999) test method is more severe than the UFAC smolder ignition test. In this test a lighted cigarette is placed between precut and preconditioned pieces of cotton battings (Figure 8), and the length of char is measured as soon as smoke is observed. Failure is defined as char lengths of $1^{\prime \prime}$ inch $(25.4 \mathrm{~mm})$ or greater.

Test standards: California Bureau of Home Furnishings and Thermal Insulation (BHFTI) smoldering ignition and open flame tests for barrier materials

BHFTI has no specific test for the fire barrier component of upholstery. The smoldering ignition test for upholstered furniture described in Cal TB 116 (California TB 116 2999) does not mention the use of fire barrier materials, but it does require the finished product or the prototype mockup to be tested with the actual components of the product sold. The Cal TB 117 (California TB 117 2999) requires the cover fabric and the loose fill materials with barrier materials to be tested for open flame ignition resistance. TB 117 does not have a specific open flame ignitability test just for barrier material; however, the proposed draft describes open flame ignition tests for cotton battings in both vertical and horizontal orientations. For the vertical open flame test, the flame application time is $10 \mathrm{~min}$ with a flame length of $4^{\prime \prime}(\sim 102 \mathrm{~mm})$, and for horizontal testing a gas flame with energy output of $0.016 \mathrm{~kW} / \mathrm{h}$ is used. To pass the test, the cotton batting must self-extinguish by the end of the 10 min test time and the mass loss must be limited to $4 \%$ of the initial mass (Wakelyn et al. 2003). The test is further modified for the mattress application with a larger sample size $\left(12^{\prime \prime} \times 12^{\prime \prime}(300 \times 300 \mathrm{~mm})\right.$ test specimen) and a flaming ignition source simulating the 16 CFR 1633 flame. The specimen is tested in the vertical as well as horizontal orientation (Figure 9). The temperature on the opposite side of the specimen is recorded using an infrared (IR) instrument. One of the most important observations during and after the test is a visual grading of the char formation. This test is material specific (exclusively for battings with at least 70\% cotton) and hence has a limited application. Barrier material with constructions other than nonwoven battings (thermally thin woven barrier fabrics) may not withstand this severe test. 


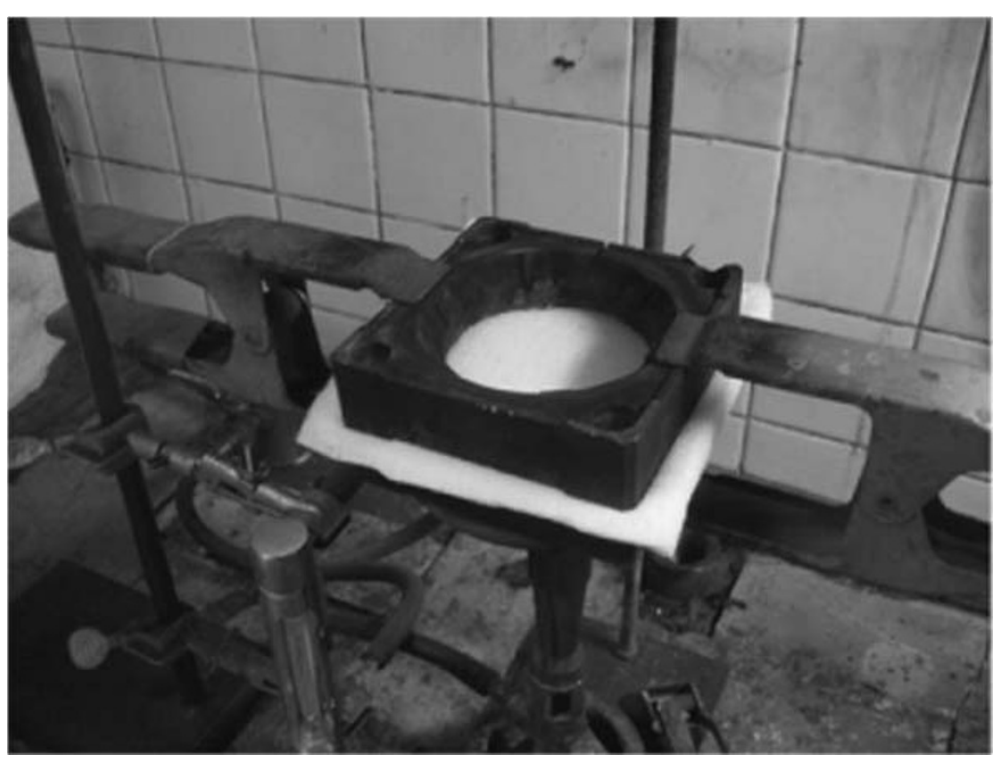

Figure 4 Meeker burner test set-up for studying char characteristics.

\section{Test standards: Barrier material development and quality} control

The ASTM and UFAC tests are commonly used in the development and quality control assessment of barrier materials. For non-woven, highloft battings, quality control measures generally include the measurement of weight, thickness, uniformity, and a burn test (draft proposed TB 117(10)). These tests are qualitative, with specific guidelines for assessing fire performance of the barrier materials. Since fire barrier materials are generally expected to be selfextinguishing, other test methods for such materials include measurements of the time of afterflame and afterglow and the extent of fire damage in terms of char length, hole size or weakened sample length.

\section{Bench scale test methods}

In an attempt to develop a clearer picture of burning behavior and to quantify a number of aspects of the barrier

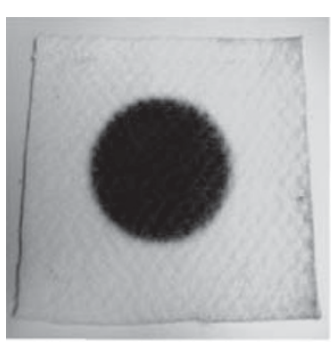

Poly(para-aramid) (60 s)

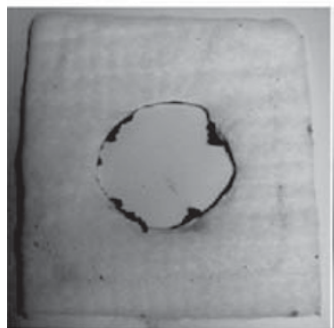

Modacrylic (5 s)

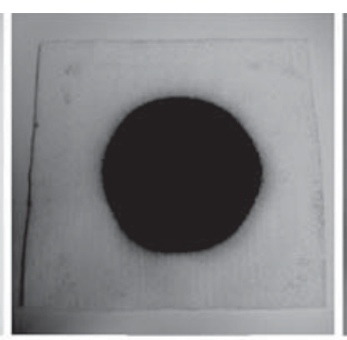

Melamine (60 s)

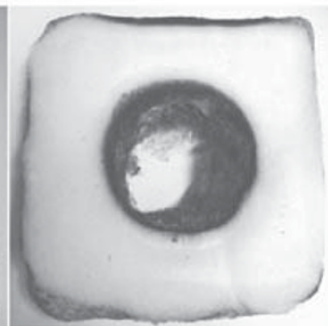

Rayon (20 s)

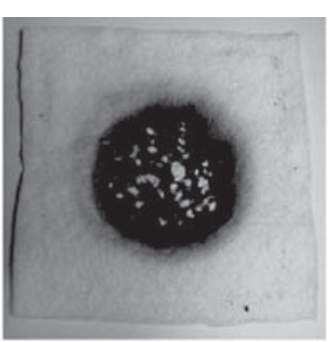

Poly(meta-aramid) (20 s)

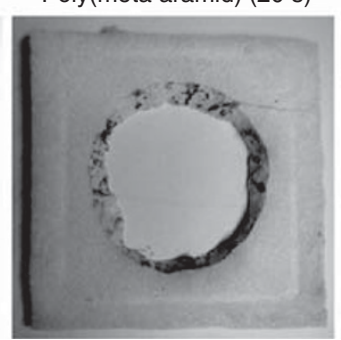

Polyester (5 s)

Figure $\mathbf{5}$ Char characteristics of nonwoven felts. Note: Values in parentheses show exposure time to open flame. 


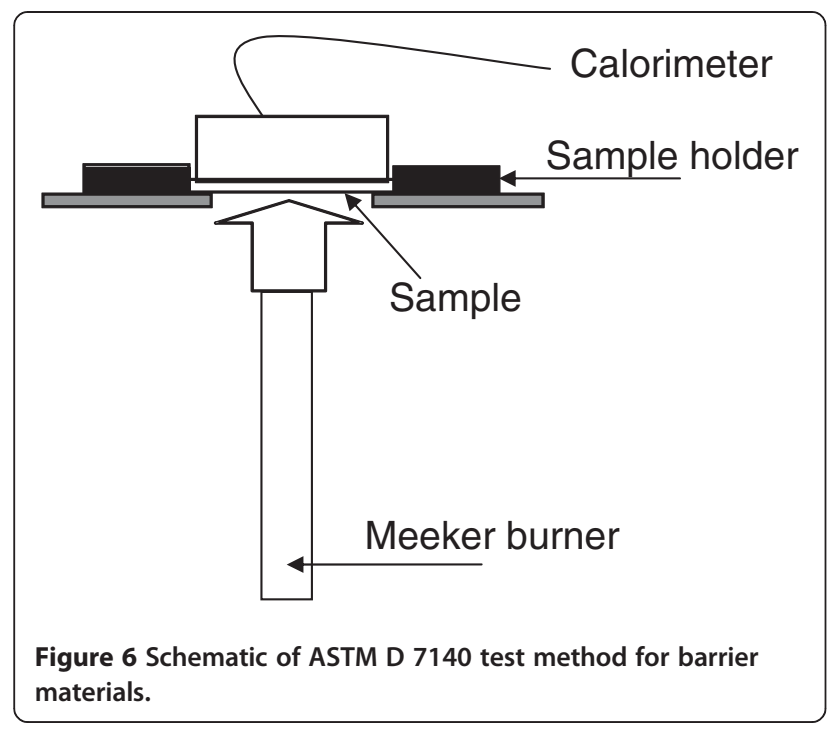

performance, it is necessary to define simple bench scale test methods based on fundamental and scientifically sound principles. Due to the economic burden of fullscale tests, these bench scale tests should empirically correlate with the full-scale performance of the product and must have predictive power. The largest hurdles in developing predictive tools have been discussed throughout this review. The flammability can drastically be impacted by the construction of fabrics and of the finished product, the type of materials, and other factors, which may mean that it is not possible to predict the full-scale behavior of the barrier material without testing the same in the context that defines the final product. However, the existing test methods described below could be helpful in screening barrier materials, thereby avoiding expensive and time-consuming full-scale furniture/mattress tests.

\section{Limiting Oxygen Index (LOI) method}

According to the ASTM D2863 test (ASTM D2863-00: Standard method for measuring the minimum oxygen concentration to support candle-like combustion of plastics 2999), the limiting oxygen index (LOI) is defined as the minimum concentration of oxygen, expressed as a volume percent, in a mixture of oxygen and nitrogen that will support the flaming combustion of a material. This technique provides a numerical measure of sample flammability, although it does not explain the burning behavior of the material. Generally, textiles having LOI values of $21 \mathrm{vol} \%$ or less burn rapidly in air, which has an oxygen concentration of $21.95 \%$ by dry volume. Textiles with values in the range $21 \mathrm{vol} \%$ to $25 \mathrm{vol} \%$ burn slowly, and those with $\mathrm{LOI} \geq 26$ vol\% exhibit some level of flame retardancy. LOI tests are primarily used to determine the relative effects of different flame retardant treatments and finishes, varying add-on finishes, or varying synergistic combinations of flame retardant compounds. However, because LOI values may be influenced by many fabric variables for a textile comprising a single fiber type, this test method is rarely used to define fabric performance by regulatory and commercial bodies (Horrocks et al. 1989). LOI methods, however, do find applications as research and development tools (Nazare \& Horrocks 2008).

\section{Thermal stability}

The thermal stability of barrier materials can be studied by thermal analysis using thermo gravimetric

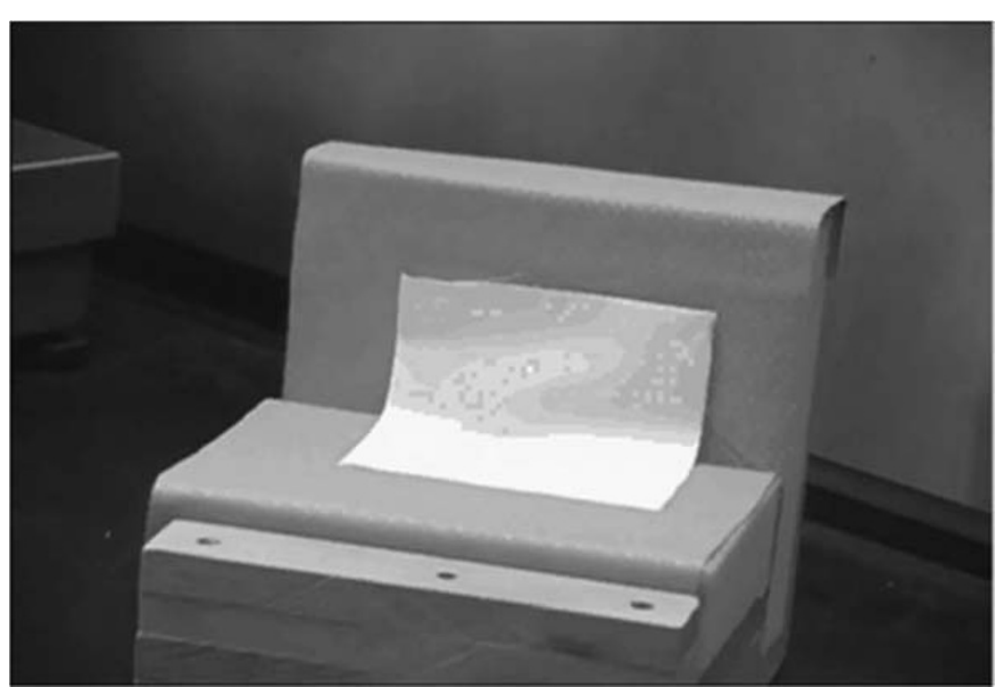

Figure 7 Mockup arrangement for UFAC smoldering ignition testing of barrier materials used in upholstered furniture. 

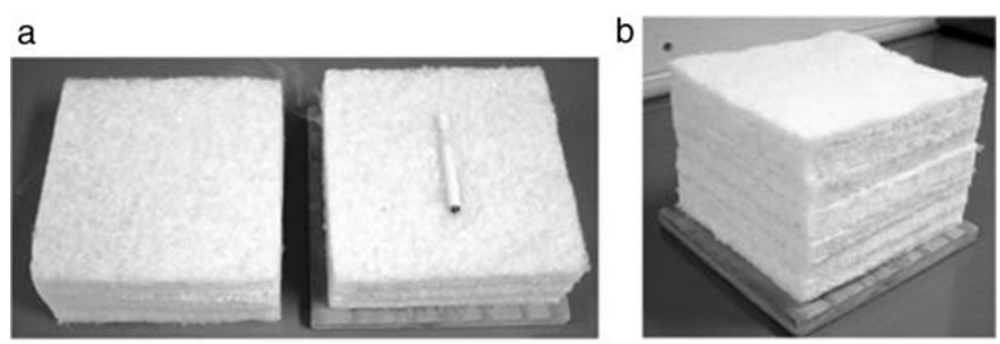

C

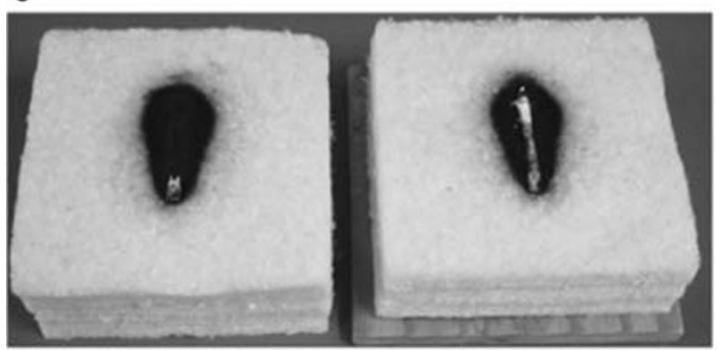

Figure 8 ASTM D 5238 test for smoldering ignition resistance of cotton batting: (a) start, (b) test in progress, and (c) end of the test. Cotton batting stack on left of (a) is placed on top of the cigarette/cotton batting stack on the right of (a) to form the testing setup in (b).

analyzer (TGA), thermo mechanical analyzer (TMA) or dynamic thermal analyzer (DMTA) techniques. Mass loss measurements at appropriate incident heat fluxes relate to volatilization and initial char formation, full char development, and subsequent char oxidation (Kandola \& Horrocks 2000). Resistance to char oxidation is a particularly desirable characteristic, since deterioration would eventually result in a failure of the barrier material to protect the PUF core.

\section{Thermal conductivity}

Fire barrier materials must limit thermal transfer into the product via conduction, convection, and radiation. As discussed above in reference to ASTM D 7140, high thermal penetration through the barrier material can cause the PUF core to ignite and accelerate the flame spread even when the barrier material is physically intact. Thermal conductivity measures the rate of conductive heat transfer through a material. This property will
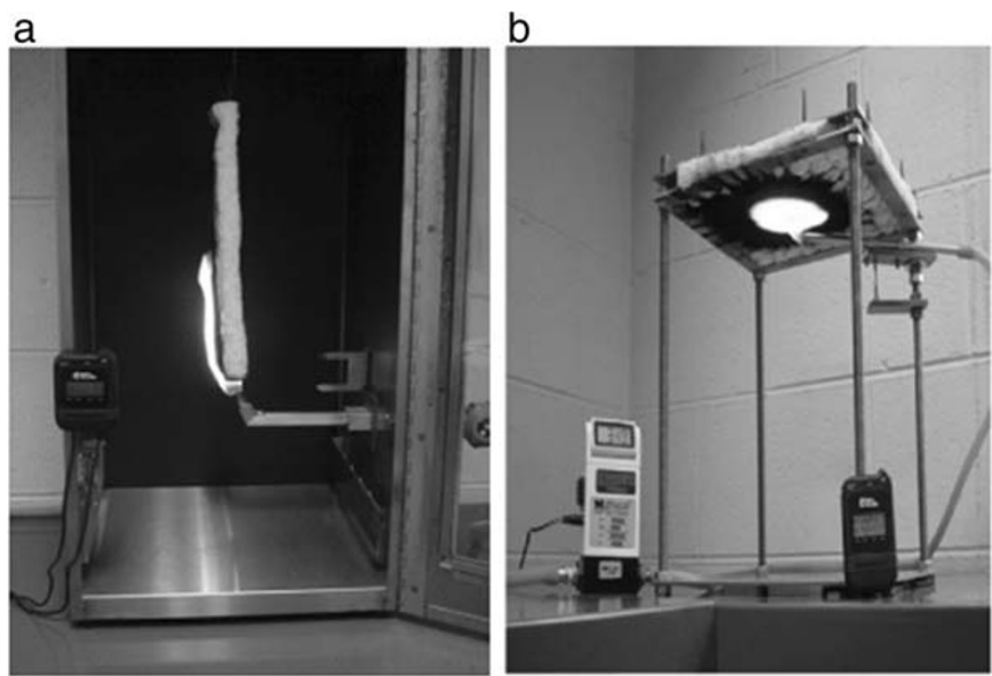

Figure 9 Modified Cal TB 117 for testing barrier flammability: (a) vertical and (b) horizontal configuration. 
vary with the amount of heat energy that a material is exposed to, and is therefore moderately temperature dependent (Lawson \& Pinder 2000). Thermal conductivity measurement of materials can be useful in assessing their effectivity as fire barriers and, to some extent predicting their performance in ASTM D 7140.

\section{Thermal Protective Performance (TPP)}

One method for screening materials for their suitability as fire barrier material is to measure the thermal protective performance (TPP) upon exposure to an incident heat flux (Figure 10). The ASTM Test Method D4108 (ASTM D4108 Standard test method for thermal protective performance of materials for clothing by open flame method 2999) can be used for this measurement. Developed by DuPont, this test method was originally designed to evaluate the thermal insulation properties of fabrics and thereby predict the incident heat energy on the outer surface of fabric systems that could cause $2^{\text {nd }}$ degree burns on human skin. For this application, the test specimen is exposed to a standard flame, and a calorimeter measures the heat flux through the specimen. A thermocouple embedded in a copper disk calorimeter is in direct contact with the back surface of the specimen and measures the thermal protective temperature (TPT). To characterize barrier materials, the specimen would be exposed to an incident heat flux for a specific time period. Low TPT values imply good insulation properties, which will help prevent the underlying cushioning from the heat and flames. The test method is applicable to woven materials, knit materials, battings and nonwoven materials.

\section{Unexposed face temperature}

The temperature of the unexposed face could also be one of the criteria for assessing barrier performance
(Babrauskas 2009). The rationale for this idea is that a rise in temperature on the unexposed side of barrier materials could ignite volatiles from underlying filling materials, thereby leading to fire propagation.

\section{Air permeability}

Fire barrier materials used in soft furnishings are porous materials. The size of pores defines the rate of air permeability, which in turn impacts the burning rate of materials within the barrier. The permeability should be kept low enough to prevent flaming combustion inside the barrier material, especially when pyrolysis gases accumulate underneath the barrier. Air permeability of a barrier material before and after heat exposures could give insight into changes in porosity and whether or not the material will act as a barrier to oxygen entering the combustion zone. The ASTM D 737 (ASTM D 737 Standard test method for air permeability of textile fabrics 2999) standard describes the method for conducting an air permeability test for various textile materials including woven, nonwoven, and knitted fabrics.

\section{Tensile strength}

Measurement of the breaking strength of samples exposed to various heat fluxes can give insight into the loss of tensile strength due to heat exposures. Determination of the breaking strength of a pre-tensioned sample exposed to a specific heating condition could be too complex, poorly defined and less reproducible. To address this issue, a simple test apparatus has been developed at the Engineering Laboratory at NIST that enables pre-tensioning of barrier material and exposure to heating conditions seen in real fires. The strength of the charred barrier sample is measured, post exposure, by adding additional weights until the char fails in tension. Test results for existing barrier

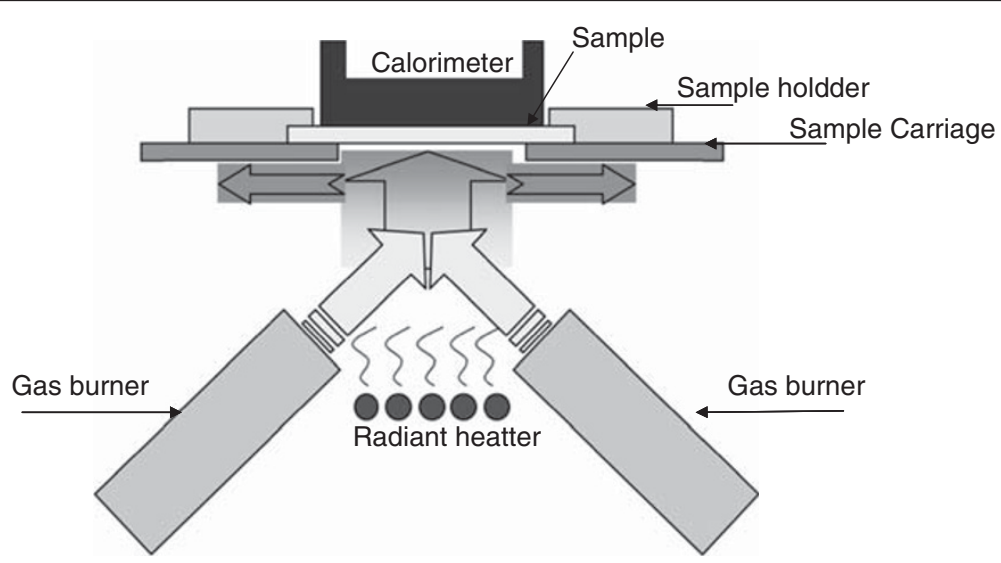

Figure 10 Schematic of TPP test device. 
material that are now being used successfully in real applications can be used to judge new barrier approaches. This NIST developed tool is still in the prototype stage, and require more testing before it is validated, but the initial results seem promising. A test protocol is expected to be released in the fall of 2012 .

\section{Future trends in fire blocking technologies}

Soft furnishings manufacturers are complying with current flammability regulations, and will likely continue to comply in the future with proposed flammability regulations, by using barrier materials. However, engineering and technical options to reach compliance are quickly diminishing because of mandated sustainability regulations for consumer products, such as Registration, Evaluation, Authorisation and Restriction of Chemical substances (REACH) ( http:// echa.europa.eu/reach_en.asp 2999), EcoLabel ( http://ec. europa.eu/environment/ecolabel/ 2999), and Environmental Product Declaration (EPD) requirements ( http://www. environmentalproductdeclarations.com/ 2999). Almost all halogenated flame retardants may be withdrawn due to the associated potential health and safety and environmental hazards during manufacturing, end-use, and disposal. Information on halogen replacement technologies is available in the literature (Horrocks et al. 2007; Wang et al. 2000; Horrocks et al. 2005; Stevens \& Horrocks 2003) and is beyond the scope of this review. The increased focus on sustainability of the final product suggests that future FR technologies not only need to satisfy these sustainability regulations, but also need to improve the fire safety of new more sustainable products, which may have different flammability issues (e.g., carbohydrate-based FR for a soy-based foam).

The nanoclays currently used to reduce flammability do not have any EHS restrictions. These nano-FRs are known to significantly improve the mechanical, thermal, barrier, and flame retardant properties of the base polymer. Polymer/clay nanocomposite fibers and nanocomposite coatings for textile applications have demonstrated significant reduction in flammability, increased tensile strength, and reduced thermal shrinkage of the fabrics (Rahatekar et al. 2009; Jain et al. 2008). However, the processing of polymer/clay nanocomposites is challenging in terms of maintaining nano-dispersion, and the influence of nanoparticles on rheological properties can be significant, particularly during fiber extrusion (Horrocks 2008b).

An innovative approach to address these challenges using the same nano-FRs is to apply a coating to the fabric or PUF after manufacturing. A novel coating method using a layer-by-layer (LbL) deposition technique is a water-based approach to fabricate nanometer- to micrometer-thick coatings on the substrate. Thin film coatings $(\sim 350 \mathrm{~nm})$ have $50 \%$ mass fraction of nano particles, but the actual loading of nano-FR is less than $1.6 \%$ mass fraction of the coated substrate. This is significantly less than most commercial FR levels ( $10 \%$ to $30 \%)$ that are used in thermoplastic applications (Kim et al. 2011). The process is highly tunable, which allows for coating polar substrates using any polymer and FR that can be dissolved/suspended in water. Another advantage of LbL coatings is that the thin film coating on the surface of the substrate is uniform and does not change the bulk properties of the substrate.

Preliminary efforts in reducing the flammability of PUF by incorporating carbon nanofibers (CNF) (Davis \& Kim 2010a) and multi wall carbon nanotubes (MWCNT) (Davis \& Kim 2010b) into LbL-fabricated thin film coatings have shown promising results. These LbL coatings were found to significantly reduce the flammability of PUF, with $55 \% \pm 6 \%$ reduction in PHRR and $21 \% \pm 3 \%$ reduction in total burn time. This reduction in flammability of the LbLcoated PUF is significantly better $(\sim 50 \%$ greater reduction in PHRR) than that reported for CNFs embedded directly into the PUF and other flame retarding technologies commercially used in PUF (Kim et al. 2011). This research has laid the foundation for using LbL to fabricate coatings on PUF and barrier materials using a range of nanoparticles and other performance enhancing additives. Davis and Grunlan (Kim et al. 2011; Davis \& Kim 2010a; Davis \& Kim $2010 b)$ continue to work on fabrication and analysis of clay coatings, cellulosic fiber coatings, and mixed additive coatings on both PUF and barrier fabrics. In addition, assessing the release of nanoparticles during aging and measuring the change in fire performance due to aging is ongoing.

These newly engineered materials, which address environmental as well as toxicological concerns, may lower heat release in future soft furnishing fires, thereby saving lives and protecting property in case of accidental fires. In addition to developing new, sustainable and superior fire blocking materials, it is also very essential to define guidelines for quantifying the performance of fire blocking barrier fabrics. These guidelines will provide a competitive advantage for soft furnishing industry to develop fire barrier fabrics that comply with full-scale fire regulations for mattresses and upholstered furniture. Current research activities in our laboratories are focused towards development of standardized testing tools and methods for quantitative evaluation of barrier effectiveness.

\section{Additional file}

Additional file 1: Table S1. Performance of various fire barrier materials in cigarette ignition, small open flame, and wooden crib tests [42]. Not tested (grey), Pass (yellow), Failed (red), No ignition $(X)$, Ignition $(\sqrt{ })$.

\section{Competing interests}

The authors declare that they have no competing interests.

Authors' contribution

All authors read and approved the final manuscript. 
Received: 19 December 2011 Accepted: 17 February 2012 Published: 23 April 2012

\section{References}

[http://ec.europa.eu/environment/ecolabel/]

[http://echa.europa.eu/reach_en.asp]

[http://www.alessandrayarns.com/about.html]

[http://www.environmentalproductdeclarations.com/]

Ahrens M (2008) Home fires that began with upholstered furniture. National Fire Protection Association. May (2008). Summary available from: [http://www. nfpa.org/assets/files/PDF/UpholsteredExecutiveSum.pdf]

Anon, Fire barrier technologies. Available at: [http://www.frsystems.ca/firebarrier. html]

ASTM D 737 - Standard test method for air permeability of textile fabrics.

ASTM D2863-00: Standard method for measuring the minimum oxygen concentration to support candle-like combustion of plastics (oxygen index).

ASTM D4108- Standard test method for thermal protective performance of materials for clothing by open-flame method.

ASTM D5238 - 10 Standard test method for smoldering combustion potential of cotton-based batting.

ASTM D7140 - 07 Standard test method to measure heat transfer through textile thermal barrier materials

Babrauskas V (2009) Unexposed-face temperature criteria in fire resistance tests: A reappraisal. Fire Safety Journal 44(6):813-818

Bourbigot S, Flambard X (2002) Heat resistance and flammability of high performance fibres: a review. Fire and Materials 26(4-5):155-168

BS 5852:2006 Methods of test for assessment of the ignitability of upholstered seating by smoldering and flaming ignition sources.

Bwalya A, Gibbs E, Lougheed G, Kashef A, Saber H (2009) Combustion of nonopenflame resistant Canadian Mattress in a roon environment.Fire and Materials Conference, 12th International Conference 2009, San Francisco, CA., 26-28 January 2009, pp. 1-2. Also available at: [http://irc.nrc-cnrc.gc.ca]

California TB 116, Requirements, Test Procedure and Apparatus for Testing the Flame Retardance of Upholstered Furniture.

California TB 117, Requirements, Test Procedures and Apparatus for Testing the Flame Retardance of Resilient Filling Materials Used in Upholstered Furniture.

California TB 603, Requirements and Test Procedure for Resistance of a Residential Mattress/Box Springs Set to a Large Open- Flame, Now replaced by 16CFR 1633

CFR 1633 (2007) Standard for the flammability (open flame) of mattress sets. Consumer Product Safety Commission. March (2007). Available from: [http://www.cpsc.gov/businfo/frnotices/fr06/mattsets.pdf]

Chattopadhyay DK, Webster DC (2009) Thermal stability and flame retardancy of polyurethanes Progress in Polymer Science 34(10):1068-1133

Chivas C, Guillaume E, Sainrat A, Barbosa V (2009) Assessment of risks and benefits in the use of flame retardants in upholstered furniture in continental Europe. Fire Safety Journal 44(5):801-807

Coles AR (2000) Flammability of upholstered furniture using the cone calorimeter. M.E. (Fire) Degree Thesis, University of Canterbury, New Zealand, 2000

Consumer Protection Act (1987) The Furniture and Furnishings (Fire) (Safety) Regulations, 1988. HMSO, London, 1988

Damant GH (1995) Cigarette ignition of upholstered furniture. Journal of Fire Sciences 13:337-349

Damant GH (1996) Use of barriers and fire blocking layers to comply with fullscale fire tests for furnishings. Journal of Fire Sciences 14:3-25

Damant GH (2009) Fire Barriers for Furnishings - Overview and Early History, Presented at NIST Fire Barrier Workshop, March 18 - 19, 2009

Damant GH. Flammability of furnishings: Someone had to be first!, In conference Proceedings of the Flame retardants' 90 Conference, Queen Elizabeth II Conference Centre, Westminster, London, UK, 17-18, January 1994, pp.242-264

Damant GH, Nurbakhsh S (1992) Heat release tests of mattresses and bedding systems. Journal of Fire Sciences 10:386-410

Damant GH, Nurbakhsh S (1994) Using California Technical Bulletin 133 to measure heat release rate tests of seating furniture. In: Fowell AJ (ed) Fire and Flammability of Furnishings and Contents of Buildings. ASTM Publication, Philadelphia, pp 83-97

Damant GH, Williams SS, McCormack JA (1983) The role of fabric in the cigarette ignition of upholstered furniture. Journal of Fire Sciences 1:309-320

Davis RD, Kim YS (2010) Fabrication, characterization and flammability testing of carbon nanofiber layer-by-layer coated polyurethane foam, NIST TN 1674.
Davis RD, Kim YS (2010) Fabrication, Characterization and flammability testing of multiwalled carbon nanotube layer-by-layer coated polyurethane foam, NIST TN 1676.

Davis RD, Ohlemiller TJ, Steckler KD (2009) Materials and fire performance testing of barrier fabrics in mattresses and upholstered furniture. Fire and Materials. 2009; 11th International Conference. Conference Papers. Proceedings. Organised by Interscience Communications Limited. January 26-28, 2009, San Francisco, CA, Interscience Communications Limited, London, England, 679-684 pp, 2009

Decabromodiphenylether (2005) An Investigation of non-halogen substitutes in electronic enclosure and textile applications. Publication of the Lowell Centre for Sustainable Production, MA, USA

Dennis ML, Handermann AC. Nonwoven highloft flame barrier. Application number 10/474395, Filed on 09/11/2002. Published on 08/21/2007

Dombrowski R (1996) Flame retardants for textile coatings. Journal of Coated Fabrics 25:224-238

Dry N. et al (2006) Flame resistant matelasse fabrics. WIPO Patent Application WO/2006/116674, Filed on April 28, 2006. Published on November 02, 2006

Eggestad J, Johnsen AC (1987) Effects of interliners on the ignitability of upholstered furniture. Journal of Fire Sciences 5:152-161

U.S. Environmental Protection Agency (2010) DecaBDE Phase-out Initiative. Available: EPA.gov

European Union, "Registration, Evaluation, Authorization and Restriction of Chemicals" (REACH), EC Reg. No 1907/2006 (2006), "Restriction of Hazardous Substances Directive" (RoHS), Dir. 2002/95/EC (2003), "Waste Electrical and Electronic Equipment Directive" (WEEE) Dir. 2002/96/EC (2003).

Fesman G, Jacobs BA (1989) Evaluating the flammability of upholstered furniture intended for public occupancies. Journal of fire sciences 7:414-425

Flambard X, Bourbigot S, Ferreira M, Vermeulen B, Poutch F (2002) Wool/paraaramid fibers blended in spun yarns as heat and fire resistant fabrics. Polym Degrad Stab 77(2):279-284

Flambard X, Bourbigot S, Kozlowski R, Muzyczek M, Mieleniak B, Ferreira M, Vermeulen B, Poutch F (2005) Progress in safety, flame retardant textiles and flexible fire barriers for seats in transportation. Polym Degrad Stab 88(1):98-105

Forsten HH (1994) Cone calorimeter studies of furniture component system. In: Fowell AJ (ed) Fire and Flammability of Furnishings and Contents of Buildings. ASTM Publication, Philadelphia, pp 105-113

Fritz TW, Hunsberger PL (1997) Testing of mattress composites in the cone calorimeter. Fire and Materials 21:17-22

Gallagher JA (1993) Interliner effect on the fire performance of upholstery materials. Journal of Fire Sciences 11:87-105

Gandhi S, Spivak SM (1994) A survey of upholstered furniture fabrics and implications for furniture flammability. Journal of Fire Sciences 12:284-312

Gann RG et al (2011) Upholstered furniture flammability research: A review of recent publications, NIST Technical Note in preparation. National Institute of Standards and Technology, Gaithersburg

Glossary of flexible Polyurethane foam technology, Joint Industry Foam Standards and Guidelines SECTION 15.0 Published: July 1994. Available from : [http://www.pfa.org/jifsg/jifsgs15.html]

Grand AF, Priest DN, Stansberry HW (1994) Burning characteristics of upholstered chairs. In: Fowell AJ (ed) Fire and flammability of furnishings and contents of buildings, ASTM STP 1233. American Society for Testing materials, Philadelphia, pp 63-82

Greene M, Miller D (2006-2008) Residential Fire Loss Estimates. Consumer Product Safety Commission report. August (2010). Available from: [http:// www.cpsc.gov/library/fire06.pdf]

Hall JR (2008) Total cost of fire in the United States. National Fire Protection Association; February (2008) Summary available from: [http://www.nfpa.org/ assets/files/PDF/totalcostsum.pdf]

Hall JR, Harwood B (1989) The national estimates approach to U.S. fire statistics. Fire Tech 25(2):99-113

Hashish F-Y, Hirsch D, Beeson H (2003) Evaluation of polyimide foam as a fire barrier for spacecraft cushion materials. Journal of Fire Sciences 21:485-501

Hendermann AC (2004) Flame resistant barriers for home furnishings. J Ind Text 33(3):159-178

Hendermann A, Bridges SA (2006) Slickened or siliconised flame-resistant fiber blends and flame barrier. US Patent Application, US, 160,454

Horrocks AR (1996) Developments in flame retardants for heat and fire resistant textiles - the role of char formation and intumescence. Polym Degrad Stab 54(2-3):143-154

Horrocks AR (2001) Textiles. In: Horrocks AR, Price D (eds) chapter 4 in Flame Retardant Materials. Woodhead Publishing Ltd, Cambridge, UK 
Horrocks AR (2008a) Flame retardant/resistant textile coatings and laminates, Chapter 6. In: Horrocks AR, Price D (eds) Advances in Flame Retardant Materials. Woodhead Publishing, Cambridge, pp 159-188

Horrocks AR (2008b) Flammability Testing. In: Horrocks AR, Price D (eds) Chapter 5 in Advances in Flame Retardant Materials. Woodhead Publishing Ltd, Cambridge, UK, pp 124-158

Horrocks AR, Tunc M, Price D. The burning behavior of textiles and its assessment by oxygen-index methods. Textile Progress, Ed. L. Cegielka. 1989;18(1/2/3)

Horrocks AR, Anand SC, Sanderson D (1993) Novel textile barrier fabrics which retain coherence and flexibility up to $900 \mathrm{deg}$ C, In Conference Proceedings of the 6th International Interflam Conference. 1993; 689-698

Horrocks AR, Anand SC, Sanderson D. Fiber-intumescent interactive systems for barrier fabrics. In conference Proceedings of the Flame retardants' 94 Conference, Queen Elizabeth II Conference Centre, Westminster, London, UK, 26-27th January 1994, pp. 117-128.

Horrocks AR, Kandola B, Padmore K, Dalton J,Owen T (2001) Comparison of cone and OSU calorimetric techniques to assess the flammability behavior of fabrics used for aircraft interiors. Proceedings of the 7th Fire and Materials Conference, San Francisco, U.S.A., 22-24th January 2001; 231.

Horrocks AR, Kandola BK, Davies PJ, Zhang S, Padbury SA (2005) Developments in flame retardant textiles - a review. Polym Degrad Stab 88(1):3-12

Horrocks AR, Davies PJ, Kandola BK, Alderson A (2007) The potential for volatile phosphorus- containing flame retardants in textile back-coatings. Journal of Fire Sciences 25:523-540

Jain R, Liu Y, Rasheed A Chae, H Gi, Kumar S (2008) Polymer/carbon nanotubes composite fibers for fire barrier application. Annual Technical Report, NIST (US Department of Commerce) Award Number: 70NANB6H6014.

Kandola BK, Horrocks AR (2000) Complex char formation in flame-retarded fiberintumescent combinations - IV. Mass loss and thermal barrier properties. Fire and Materials 24(6):265-275

Kemmlein S, Herzke D, Law RJ (2009) Brominated flame retardants in the European chemicals policy of REACH-Regulation and determination in materials. J Chromatogr A 1216(3):320-333

Kim YS, Davis RD, Cain AA, Grunlan JC (2011) Development of layer-by-layer assembled carbon nanofiber-filled coatings to reduce polyurethane foam flammability. Polymer 52:2847-2855

Knoff WF, Hall W (2006) Flame resistant fabric useful as a batting in mattresses and upholstery. US Patent Application, US, 172,649

Kozlowski R, Mieleniak B, Muzyczek M (1999) Fire resistant composites for upholstery. Polym Degrad Stab 64(3):511-515

Kozlowski R, Mieleniak B, Muzyczek M, Kubacki A (2002) Flexible fire barriers based on natural nonwoven textiles. Fire and Materials 26(4):243-246

Krämer RH, Zammarano M, Linteris GT, Gedde UW, Gilman JW (2010) Heat release and structural collapse of flexible polyurethane foam. Polym Degrad Stab 95(6):1115-1122

Lawson JR and Pinder TA (2000) Estimates of thermal conductivity for materials used in fire fighter's protective clothing, NISTIR 6512.

Lefebvre J, Bastin B, Le Bras M, Duquesne S, Ritter C, Paleja R, Poutch F (2004) Flame spread of flexible polyurethane foam: comprehensive study. Polym Test 23(3):281-290

Levchik SV, Weil ED (2004) Thermal decomposition, combustion and fireretardancy of polyurethanes - a review of the recent literature. Polym Int 53 (11):1585-1610

Ma X (2007) Multilayered fire blocking fabric structure having augmented fire blocking performance. US Patent Application, US, 99,533

Mater DL (2007) Handermann AC., Nonwoven highloft barrier, US Patient Application, US 7259117, 2007

Memorandum to D (2004) Ray from Linda Fansler, Exploratory test of barrier materials. Consumer Product Safety Commission, Washington

Nazare S (2009) Sustainable 'Environmentally Friendly' Flame Retardant Textiles. Chapter 14. In: Blackburn R (ed) Sustainable Textiles. Woodhead Publishing Ltd, Cambridge

Nazare S, Davis R (2011) Assessment of factors affecting fire performance of mattresses: A review, NIST Technical Note in preparation. National Institute of Standards and Technology, Gaithersburg

Nazare S, Horrocks AR (2008) Flammability Testing. In: Hu J (ed) Chapter 11 in Fabric Testing. Woodhead Publishing Ltd, Cambridge, UK

Nurbakhsh S, Mc Cormack J (1998) A review of the Technical Bulletin 129 full scale test method for flammability of mattresses for public occupancies. Journal of Fire Sciences 16:105-124
Ohlemiller TJ (2008) On the Criteria for Smoldering Ignition in the CFR 1632 Cigarette Test for mattresses, NIST Technical Note 1601. National Institute of Standards and Technology, Gaithersburg

Ohlemiller TJ, Gann RG (2002) Estimating reduced fire risk resulting from an improved mattress flammability standard, NIST Technical Note 1446. National Institute of Standards and Technology, Gaithersburg

Ohlemiller TJ, Gann RG (2003) Effect of bed clothes modifications on fire performance of bed assemblies, NIST Technical Note 1449. National Institute of Standards and Technology, Gaithersburg

Ohlemiller TJ, Shields J (1995) Behavior of mock-ups in the California Technical Bulletin 133 test protocol: Fabric and barrier effects, NISTIR 5653. National Institute of Standards and Technology, Gaithersburg

Ohlemiller TJ, Shields JR (2008) Assessment of medium-scale, polyurethane foam flammability test, NIST Technical Note 1495. National Institute of Standards and Technology, Gaithersburg

Parikh DV, Sachinvala ND, Sawhney APS, Robert KQ, Graves EE, Calamari TA, Chen Y, Jirsak O (2003) Flame Retardant Cotton Blend Highlofts. Journal of Fire Sciences 21:383-395

CFR Part 1634 (2008) Standard for the flammability of residential upholstered furniture (proposed rule). Consumer Product Safety Commission. March (2008). Available from: [http://www.cpsc.gov/businfo/frnotices/fr08/furnflamm.pdf]

Paul KT, Reimann KA, Sundstorm B (2004) Furniture and Furnishings, Chapter 13 in Plastics flammability handbook: principles, regulations, testing, and approval. Troitzsch J. (Editor), Hanser Gardner Publications, Inc., Cincinnati, 580-608.

Rahatekar SS, Rasheed A, Jain R, Zammarano M, Koziol KK, Windle AH, Gilman JW, Kumar S (2009) Solution spinning of cellulose carbon nanotube composites using room temperature ionic liquids. Polymer 50(19):4577-4583

Reduced risk of furniture fire hazard, [http://www.nist.gov/el/fire_protection/ buildings/reduced_risk_of_furniture_fire_hazard.cfm], viewed on 6/1/11.

Schumann JG, Hartzell GE (1989) Flaming combustion characteristics of upholstered furniture. Journal of Fire Sciences 7:386-402

Shanley LA, Slaten BL, Shanley P, Broughton R, Hall D, Baginski M (1994) Thermal properties of novel carbonaceous fiber battings. Journal of Fire Sciences $12: 238-245$

Singh $H$, Jain AK (2009) Ignition, combustion, toxicity, and fire retardancy of polyurethane foams: a comprehensive review. J Appl Polymer Sci 111(2):111-1143

Small JD, Walton JH (2007) US Patent Application US 2007 141,938

Stevens GC, Horrocks AR (2003) Textile back-coating environmental challenges for the UK furnishing fabrics industry: Release and exposure of flame retardant species. J Ind Text 32:267-278

Sundström B (1995) Fire Safety of Upholstered Furniture-The final report on the Combustion Behavior of Upholstered Furniture (CBUF) Program. Interscience Communications Ltd, London

Technical Bulletin 129 (1992) Flammability Test procedure for mattresses for use in public buildings, October 1992, State of California Department of Consumer Affairs Bureau of Home Furnishings and Thermal Insulation 3485 Orange Grove Avenue North Highlands, CA 95660-5595. [http://www.bhfti.ca. gov/industry/bulletin.shtml]

Technical Bulletin 133 (1991): Flammability test procedure for seating furniture for use in public occupancies, January 1991 State of California Department of Consumer Affairs Bureau of Home Furnishings and Thermal Insulation 3485 Orange Grove Avenue North Highlands, CA 95660-5595

Ticking Trends (2005) Suppliers cope with fast-changing demands, Featured Article in BedTimes, October, [http://www.bedtimesmagazine.com/Articles/ 2005/October/TickingTrends.html]

Toxicological Risks of Selected Flame Retardant Chemicals, National Research Council, National Academy of Sciences, US (2000)

Upholstery Furniture Action Council, UFAC Central Box 2436 High Point, NC 27261 [http://www.ufac.org/method1.htm]

US Patent Application 20070161312 - Fiberglass fire barrier for mattresses. Filed on January 11, 2006. Published on July 12, 2007

Wakelyn PJ, Wolf S, Oliver K (2003) Cotton batting fire-blocking barriers for soft furnishings. Presented at the 14th Annual Business Communications Company. Inc. (BCC) Conference on Flame Retardancy, Stamford, CT

Wakelyn PJ, Adair PK, Barker RH (2005) Do open flame ignition resistance treatments for cellulosic and cellulosic blend fabrics also reduce cigarette ignitions? Fire and Materials 29:15-26 

interactions and the effect of replacement by phosphorus-containing agents. Journal of Fire Sciences 18:265-294

Weil ED, Levchik SV (2008) Flame retardants in commercial use or development for textiles. Journal of Fire Sciences 26:243-281

Weil ED, Yang C (2008) Textile flame retardancy-State of art and recent progress, 19th Annual BCC Conference on Flame Retardancy. BCC Communications, 911, Stamford, Connecticut

doi:10.1186/2193-0414-1-1

Cite this article as: Nazaré and Davis: A review of fire blocking

technologies for soft furnishings. Fire Science Reviews 2012 1:1.

\section{Submit your manuscript to a SpringerOpen ${ }^{\circ}$} journal and benefit from:

- Convenient online submission

- Rigorous peer review

- Immediate publication on acceptance

- Open access: articles freely available online

- High visibility within the field

- Retaining the copyright to your article

Submit your next manuscript at $\gg$ springeropen.com 